\title{
Article \\ Comprehensive Review and Future Research Directions on Dynamic Faceted Search
}

\author{
Mohammed Najah Mahdi ${ }^{1, *} \mathbb{C O}$, Abdul Rahim Ahmad ${ }^{2}$, Hayder Natiq ${ }^{3}{ }^{\circ}$, Mohammed Ahmed Subhi ${ }^{4}$ \\ and Qais Saif Qassim ${ }^{5}$ \\ 1 Institute of Informatics and Computing in Energy, Universiti Tenaga Nasional, Kajang 43000, Malaysia \\ 2 College of Computing and Informatics (CCI), Universiti Tenaga Nasional, Kajang 43000, Malaysia; \\ Abdrahim@uniten.edu.my \\ 3 Department of Computer Technology, Information Technology College, Imam Ja'afar Al-Sadiq University, \\ Baghdad 10064, Iraq; hayder.natiq@sadiq.edu.iq \\ 4 Department of Computer Engineering Techniques, Al Hikma University College, Baghdad 10064, Iraq; \\ mohammed.subhi@hiuc.edu.iq \\ 5 College of Technology, University of Technology and Applied Sciences, Ibri 511, Oman; \\ qais.aljanabi@ibrict.edu.om \\ * Correspondence: Najah.Mahdi@uniten.edu.my
}

Citation: Mahdi, M.N.; Ahmad, A.R.; Natiq, H.; Subhi, M.A.; Qassim, Q.S Comprehensive Review and Future Research Directions on Dynamic Faceted Search. Appl. Sci. 2021, 11, 8113. https://doi.org/10.3390/ app11178113

Academic Editor: Francisco García-Sánchez

Received: 3 July 2021

Accepted: 14 August 2021

Published: 31 August 2021

Publisher's Note: MDPI stays neutral with regard to jurisdictional claims in published maps and institutional affiliations.

Copyright: (c) 2021 by the authors. Licensee MDPI, Basel, Switzerland. This article is an open access article distributed under the terms and conditions of the Creative Commons Attribution (CC BY) license (https:// creativecommons.org/licenses/by/ $4.0 /)$.

\begin{abstract}
In modern society, the increasing number of web search operations on various search engines has become ubiquitous due to the significant number of results presented to the users and the incompetent result-ranking mechanism in some domains, such as medical, law, and academia. As a result, the user is overwhelmed with a large number of misranked or uncategorized search results. One of the most promising technologies to reduce the number of results and provide desirable information to the users is dynamic faceted filters. Therefore, this paper extensively reviews related research articles published in IEEE Xplore, Web of Science, and the ACM digital library. As a result, a total of 170 related research papers were considered and organized into five categories. The main contribution of this paper is to provide a detailed analysis of the faceted search's fundamental attributes, as well as to demonstrate the motivation from the usage, concerns, challenges, and recommendations to enhance the use of the faceted approach among web search service providers.
\end{abstract}

Keywords: academic search engines; exploratory search; faceted navigation; faceted search; faceted taxonomy; information filtering; web technologies

\section{Introduction}

Search Engines (SEs) have become some of the most necessary tools for Internet users. Generally, an SE is an information retrieval (IR) application that locates the most relevant information and then accurately conveys the results to the users based on the specified queries [1-5]. Meanwhile, exploratory search (ES) has a similar mechanism as SEs except that it further narrows down the search results using faceted classification. It, therefore, has the potential to give a complete overview of a topic based on fewer queries [6,7]. However, both SEs and ES have specific issues, such as the user's poor vocabulary and search-result overload challenges [8].

Faceted search (FS) is considered as one of the ES techniques that aids users in exploring items of interest within such a vast data repository. The FS technique provides relevant results with less user effort and reduces information overload $[9,10]$. Several conventional search filters could narrow down the search results; however, FS is more effective and highly flexible compared to conventional filters, especially with increased search complexity. Moreover, the interface of FS contributes to preventing users from losing track of their searches. Therefore, FS has received significant attention from researchers in the last decade [11,12]. 
The main research objective of this work is to determine the requirements and motivations that enhance the understanding of the FS implementation. The work reviews related works based on several perspectives, including (1) the scope of research, (2) the purpose of the study, and (3) the performance evaluation measures. Moreover, the work considered some other points of interest, including the architecture, applications, issues, research questions, motivation, recommendation criteria, and open challenges in using FS. This paper applies the Systematic Literature Review (SLR) method provided by [13-15] to analyze the existing literature. The SLR method is suitable for pinpointing the main idea of FS and is used to refine and provide a landscape for future research to identify relevant issues, challenges, and the line of research in FS. The remainder of this paper is organized as illustrated in Figure 1.

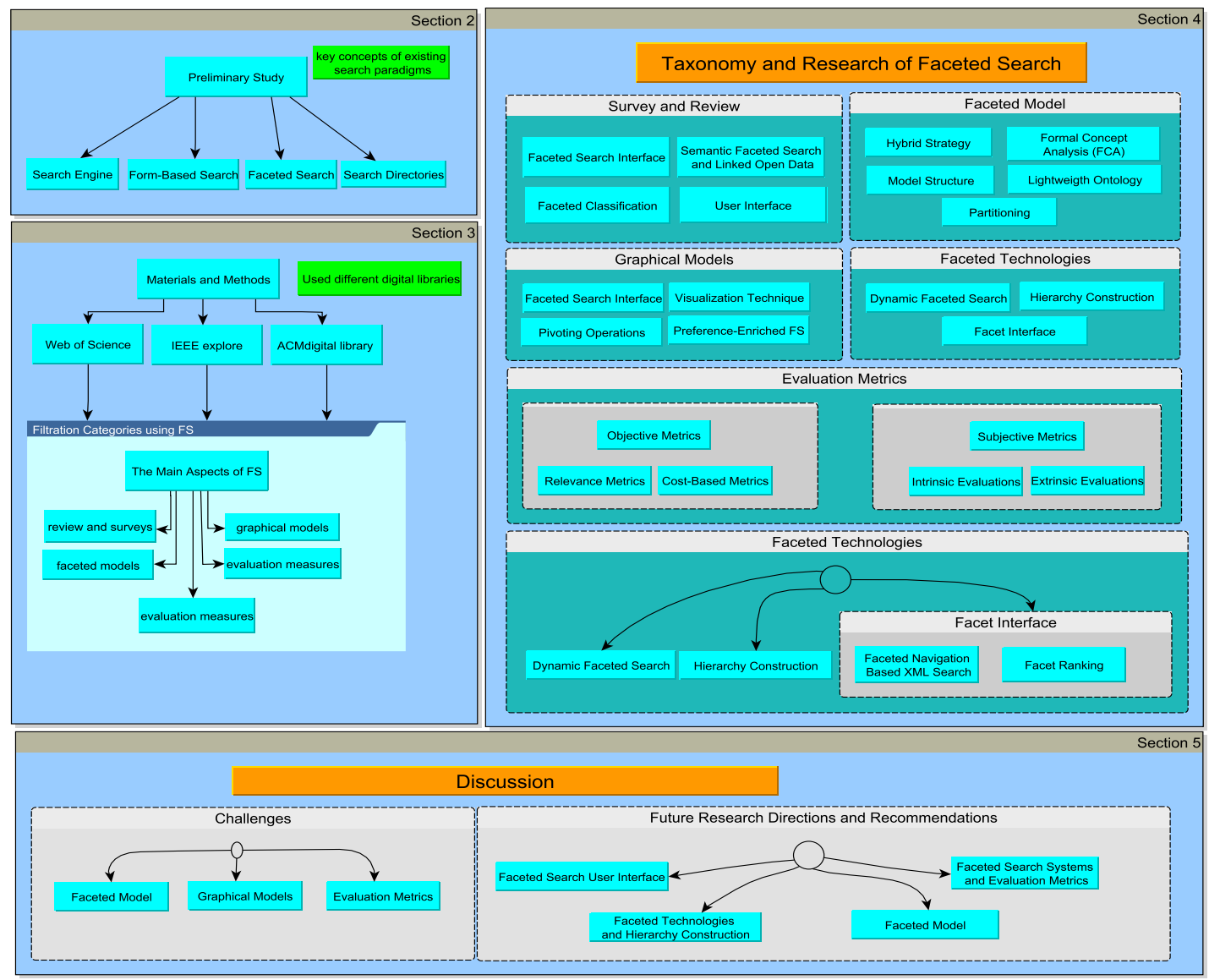

Figure 1. Diagrammatic view of the organization of this survey paper.

\section{Preliminary Study}

This section presents the fundamental concepts of some existing search paradigms, including SEs, search directories, form-based search, and FS. Then, a comparative study of these search paradigms is presented.

\subsection{Search Engines}

The main workflow of any conventional search engine is collecting keywords from the websites' index pages, whereas a web crawler finds information to put into the index file. Although most conventional search engines follow standard methods, they may still use different features, algorithms, pages, or files to optimize the results. Moreover, they usually utilize different ranking algorithms to determine the order of the results based on predefined criteria. 


\subsection{Search Directories}

Search directories perform the same function as SEs, but they do not use computers to rank pages; instead, they utilize crowdsourcing for page ranking. People visit the submitted site and approve the site for a relevant directory. Yahoo! Directory was one of the best-known examples of search directories, although many people confuse it with an SE.

\subsection{Form-Based Search}

This approach supports an advanced query interface to perform complicated searches. The full-text search dialogue box runs in a form-based tab. Using multiple queries can narrow the search by selecting categories in the full-text search tab in the search pane. Once the user understands how to use the search operators, the user can also type different search queries in the full-text search tab.

\subsection{Faceted Search}

The term facet means "little face" and is often used to describe one side of a manysided object, especially a cut gemstone. In the context of information science, where the item being described is an information object, facets could refer to the object's author, date, topic, etc. The term was introduced by Ranganathan, an Indian mathematician, when he presented a facet analysis theory in the 1930s [16]. Ranganathan applied the principles of faceted classification to organize all of the human knowledge in libraries using five main facets, including (1) personality, (2) matter or property, (3) energy, (4) space, and (5) time.

Faceted search is a technique that involves enhancing conventional search engines by integrating an improved navigation system. This allows users to narrow down search results by applying multiple filters based on suggested categories. A faceted classification system semantically categorizes the search results into various explicit dimensions, called facets, enabling the categories to be accessed and ordered in multiple ways rather than in a single, predetermined taxonomic order $[17,18]$. Several faceted search systems have been designed and deployed during the last two decades. It is worth mentioning that the system's success in supporting end-users depends on the details of the domain of interest (e.g., searcher's tasks, familiarity with the facets, etc.). A summary of the essential components of faceted search is outlined in Figure 2 below. Most faceted search-enabled engines show the query, the facet structure, the previously specified subset of results, and sometimes, a detailed view of an individual item. Furthermore, Table 1 lists the comparison between FS with other search paradigms, which clearly shows the main characteristics of these search mechanisms.

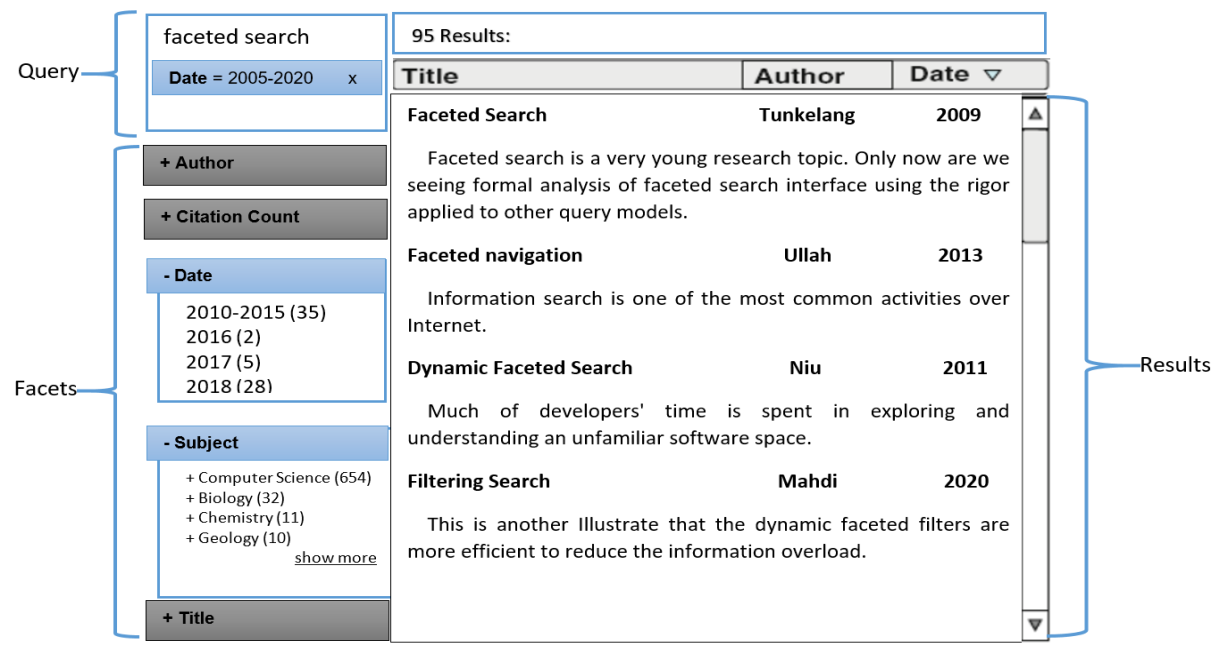

Figure 2. Faceted search, interface example, illustrating facet browsing, searching, and the tight coupling of the two. 
Table 1. Comparison of faceted search with other search paradigms.

\begin{tabular}{|c|c|c|c|c|}
\hline Criteria & Faceted Search & Search Engine & Search Directories & Form-Based Search \\
\hline Search Interface & $\begin{array}{c}\text { It uses dynamic and } \\
\text { multidimensional } \\
\text { taxonomies to satisfy } \\
\text { various search needs [19]. }\end{array}$ & $\begin{array}{l}\text { Crawlers visit a website, read } \\
\text { the information on that site } \\
\text { and the meta tags and } \\
\text { download documents. Then, } \\
\text { the crawler returns all the } \\
\text { information to a central } \\
\text { repository of the SE, which } \\
\text { indexes the data, for example } \\
\text { Google. }\end{array}$ & $\begin{array}{l}\text { A directory offers a } \\
\text { hierarchical representation of } \\
\text { hyperlinks to web pages and } \\
\text { presentations, broken down } \\
\text { into topics and subtopics. }\end{array}$ & $\begin{array}{l}\text { It provides multiple } \\
\text { query options. }\end{array}$ \\
\hline $\begin{array}{l}\text { Support Previous } \\
\text { Knowledge }\end{array}$ & $\begin{array}{l}\text { Handles uncertainty in the } \\
\text { search and the possible } \\
\text { lack of knowledge [7]. }\end{array}$ & $\begin{array}{l}\text { It searches documents for } \\
\text { specific keywords and returns } \\
\text { a list of documents. }\end{array}$ & $\begin{array}{l}\text { Human editors commonly } \\
\text { review and classify the web } \\
\text { pages and presentations, } \\
\text { which are added to } \\
\text { the directory. }\end{array}$ & Similar to FS. \\
\hline Discovery Function & $\begin{array}{l}\text { (1) It refines search results } \\
\text { using different facets; } \\
\text { (2) the number of data } \\
\text { items in each category } \\
\text { can be used in the } \\
\text { next navigation. }\end{array}$ & $\begin{array}{l}\text { The SE allows the user to ask } \\
\text { for content that meets specific } \\
\text { criteria and retrieve a list of } \\
\text { references that match } \\
\text { these criteria. }\end{array}$ & $\begin{array}{l}\text { Web directories collect } \\
\text { different resources. }\end{array}$ & Similar to SE. \\
\hline $\begin{array}{l}\text { Diversification of } \\
\text { Search Results }\end{array}$ & $\begin{array}{l}\text { It uses only a small } \\
\text { number of facet terms. }\end{array}$ & $\begin{array}{l}\text { The user enters search words } \\
\text { into the SE interface, which is } \\
\text { typically a web page with an } \\
\text { input box. }\end{array}$ & $\begin{array}{l}\text { Although many web } \\
\text { directories offer a search } \\
\text { functionality of some kind, } \\
\text { search directories are } \\
\text { fundamentally different from } \\
\text { SEs in two ways. }\end{array}$ & Similar to SE. \\
\hline Ranking & $\begin{array}{l}\text { It supports facet and } \\
\text { searches result in } \\
\text { rankings. }\end{array}$ & $\begin{array}{l}\text { It applies and parses the } \\
\text { search request into a form } \\
\text { that the SE can understand. } \\
\text { The SE then executes the } \\
\text { search operation on index files. } \\
\text { The SE interface returns the } \\
\text { search results to the user } \\
\text { after ranking. }\end{array}$ & $\begin{array}{l}\text { Most directories are edited by } \\
\text { humans, and their } \\
\text { corresponding URLs are } \\
\text { manually gathered by } \\
\text { crawlers, but submitted by site } \\
\text { owners. }\end{array}$ & Similar to SE \\
\hline $\begin{array}{l}\text { Main Advantage of FS } \\
\text { amongst Other Types }\end{array}$ & $\begin{array}{l}\text { (1) It guides potentially } \\
\text { interesting subsets of the } \\
\text { document collection; (2) it } \\
\text { explores items of interest } \\
\text { within a vast data } \\
\text { repository; (3) it provides } \\
\text { access to unstructured } \\
\text { data whilst maintaining } \\
\text { the refining capability of } \\
\text { faceted navigation. }\end{array}$ & $\begin{array}{l}\text { It forces the user to browse } \\
\text { through long lists. Such a } \\
\text { method is ineffective when } \\
\text { searchers are unable to define } \\
\text { their search precisely. }\end{array}$ & $\begin{array}{l}\text { (1) Lists in web directories are } \\
\text { sometimes outdated if humans } \\
\text { were unable to edit and verify } \\
\text { them for a certain amount of } \\
\text { time; (2) the unavailability of } \\
\text { crawlers indicates that the } \\
\text { URL must be manually } \\
\text { submitted to the search } \\
\text { directory for users to discover } \\
\text { the site, for example Google } \\
\text { Directory. }\end{array}$ & $\begin{array}{l}\text { It is slow because } \\
\text { users have to write } \\
\text { their search queries } \\
\text { and know how to use } \\
\text { search operators. }\end{array}$ \\
\hline
\end{tabular}

\subsection{Research Questions}

In view of conducting a systematic literature review, the research questions play a prominent role in deciding the search strategy and analysis. We identified the following Research Questions (RQs) for this research:

RQ1. What does the existing research literature reveal about the faceted search approach of web search service providers?

RQ2. What are the primary aims, vision, and trends for faceted search, and what research can be highlighted in this area?

RQ3. What are the existing gaps for research prospects in the faceted search approach for web search services?

RQ4. What are the existing motivations for usage, concerns, challenges, and recommendations to enhance the faceted approach of web search service providers? 
RQ5. What are the points of interest, such as the architecture, applications, issues, research questions, motivations, recommendation criteria, and open challenges, in using faceted search?

\section{Theoretical Foundations}

For the purposes of this review, we broke down the underlying components of faceted search into five primary categories, collecting the articles in these five aspects based on the papers of Gary Marchionini and Ryen W. White as follows:

1. Review and survey: The current state-of-the-art of faceted search and its applications are well described and summarized in the recently published survey and review articles and the technological challenges and concerns of faceted search;

2. Faceted models: We review the currently available literature concerning faceted search to provide a research overview of the practices and guidelines for developing effective faceted search interfaces used in research to support users' needs to understand and explore information $[8,18]$;

3. Faceted technologies: We focus on the fundamental idea of FS, which is to solicit and capture keywords supplied by a user from which to prune out branches of the hierarchy irrelevant to the user's informational need. A taxonomy can serve as more than a means to representing knowledge: its organization of information can also enable us to make information accessible and findable [8];

4. Graphical models: We discuss visualized category overviews of the information space and focus on the dynamic filtering and exploration of the result set by tightly coupling the browsing and searching functions [20,21];

5. Evaluation measures: To evaluate exploratory search systems, we must target the longer-term effect on the user of using this cognitive prosthetic and the current task performance. Evaluation metrics facilitate the incremental improvement of search technologies by assessing system performance and reducing comparisons between experimental systems. Process-specific measures of learning, mental transformation, confidence, engagement, and affect are essential and result in relevance and utility across multiple query iterations and search sessions [6,22].

\section{Materials and Methods}

As mentioned in the Introduction, in this research, we followed the SLR method to collect the related research articles based on two concepts: "faceted search" and "refining information". The research article collection was carried out via three reputed digital libraries; (1) Web of Science, as it provides multidisciplinary research articles in the fields of science; (2) IEEE explore, which provides articles specialized in the field of electrical and electronics engineering; (3) the ACM digital library, which has a comprehensive database for computing and information technology.

Many searches on the three mentioned databases were performed in July 2021 using several keywords (or phrases) such as "faceted search", "faceted-search", "faceted model", "faceted taxonomy", "faceted", "faceted applications", "faceted browsing", and "faceted classification". The keywords were only slightly different. Subsequently, these keywords were joined using the conjunctions "OR" and "AND" followed by "Refining Information". Figure 3 shows the search queries that were used in this work. We excluded some results corresponding to letters, magazine articles, and book chapters. The main goal of this exclusion was to obtain the most recent scientific articles and enhance the FS application's capability to refine information. Then, the results were divided into two classes: (1) general and (2) coarse-gained. The latter is discussed in five subsequent sections obtained from the study results in which the Google Scholar SE was utilized to define the study's direction.

The significance of the collected articles was evaluated to retain the most related articles among a large number of collected literature articles. Moreover, the included articles were categorized based on two criteria: (1) performing the initial screening to 
identify the relevant results; (2) applying three iterations in the filtering process to remove the redundant and duplicated articles.

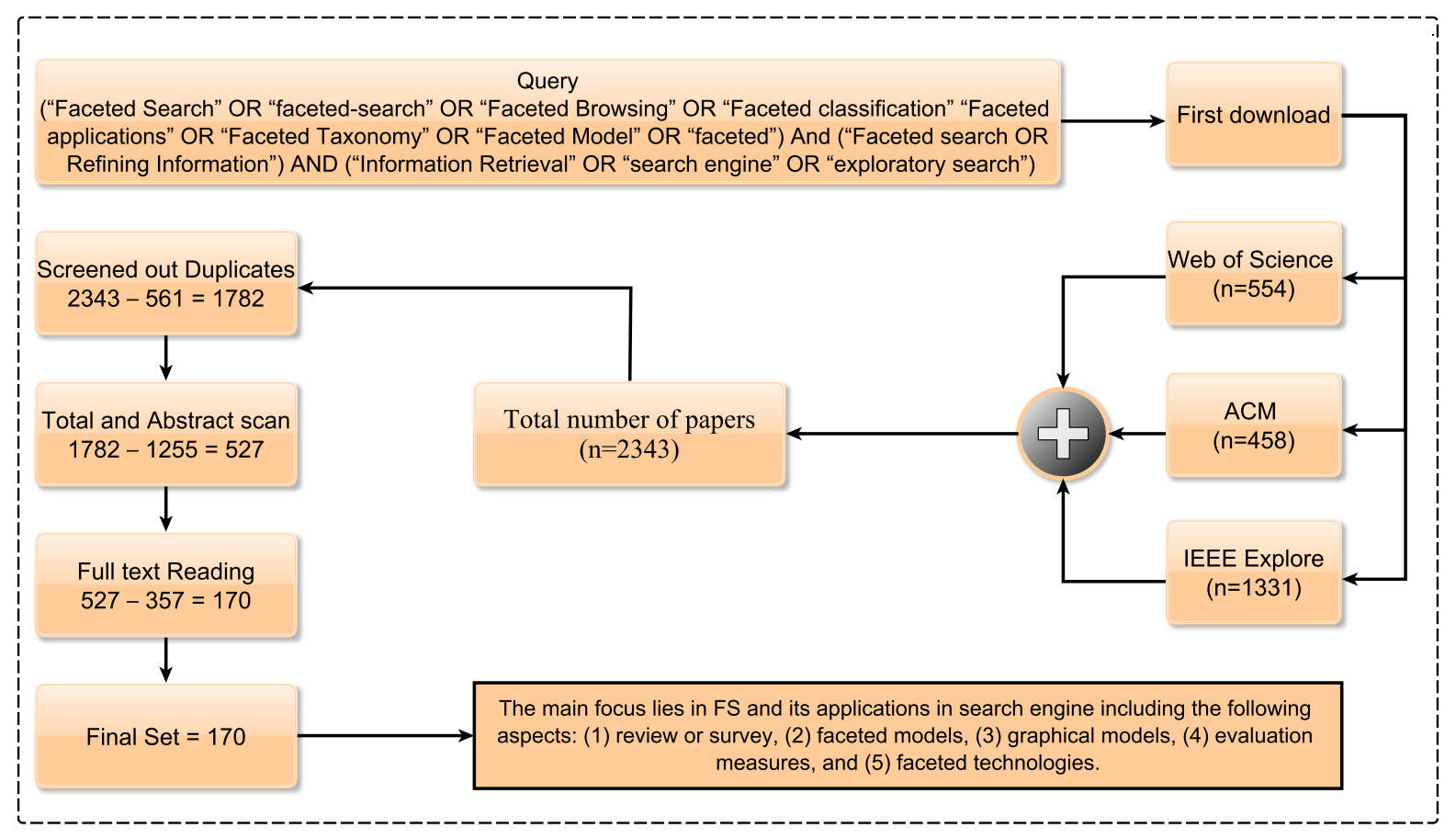

Figure 3. Research methodology guideline.

As highlighted earlier, an article was excluded if it did not satisfy the selection criteria listed as follows: (1) the English language is not the language used to write the paper; (2) faceted search and/or information refining were the main focus of the paper; (3) the research interest in the paper was only concentrated on FS without information refinement. Moreover, after the second exclusion cycle, the articles could be eliminated if ES was not included or: (1) the contribution of the paper did not consider any aspects of refining information based on FS; (2) the discussion in the paper was only focused on refining information based on FS and did not consider any other topic.

In this work, articles underwent extensive filtration, whereby the remaining articles were later categorized into five categories based on the proposed methods to enhance FS in refining information. The categories were: (1) review and surveys, (2) faceted models, (3) graphical models, (4) evaluation measures, and (5) faceted technologies. Subsequently, further subcategorization was performed according to the authors' writing and presentation of the articles to readers.

Figure 3 illustrates our results where there were 2343 research articles gathered based on the user queries, of which 554 were obtained from WOS, 1331 from IEEE, and 458 from ACM digital libraries. All selected articles were published between 2005 and 2021. These articles were later divided into three groups: (1) 561 redundant articles, (2) 1255 irrelevant based on the titles and abstracts, and (3) the 170 articles that fell within the FS search criteria.

Figure 4 presents the statistics of the different categories above for the articles related to FS. In the figure, it can be seen that the 170 articles from the three databases were divided into review and surveys (25), faceted models (35), graphical models (30), evaluation measures (36), and faceted technologies - those that describe enhancement to FS (44).

Figure 5 shows the statistics of the articles based on the publication year between 2005 and 2021. For each year, the figure shows the number of research articles for each of the five categories. It can be seen that in the early years, such as 2005 , only four articles were published. Between 2006 and 2008, the number increased gradually from six in 2006 to 
fifteen in 2009. From 2010 onwards, it can be seen that the number of publications was consistent until 2020, where the number of publications reached up to 37 research articles. This indicates the increased research trend towards the faceted search concept.

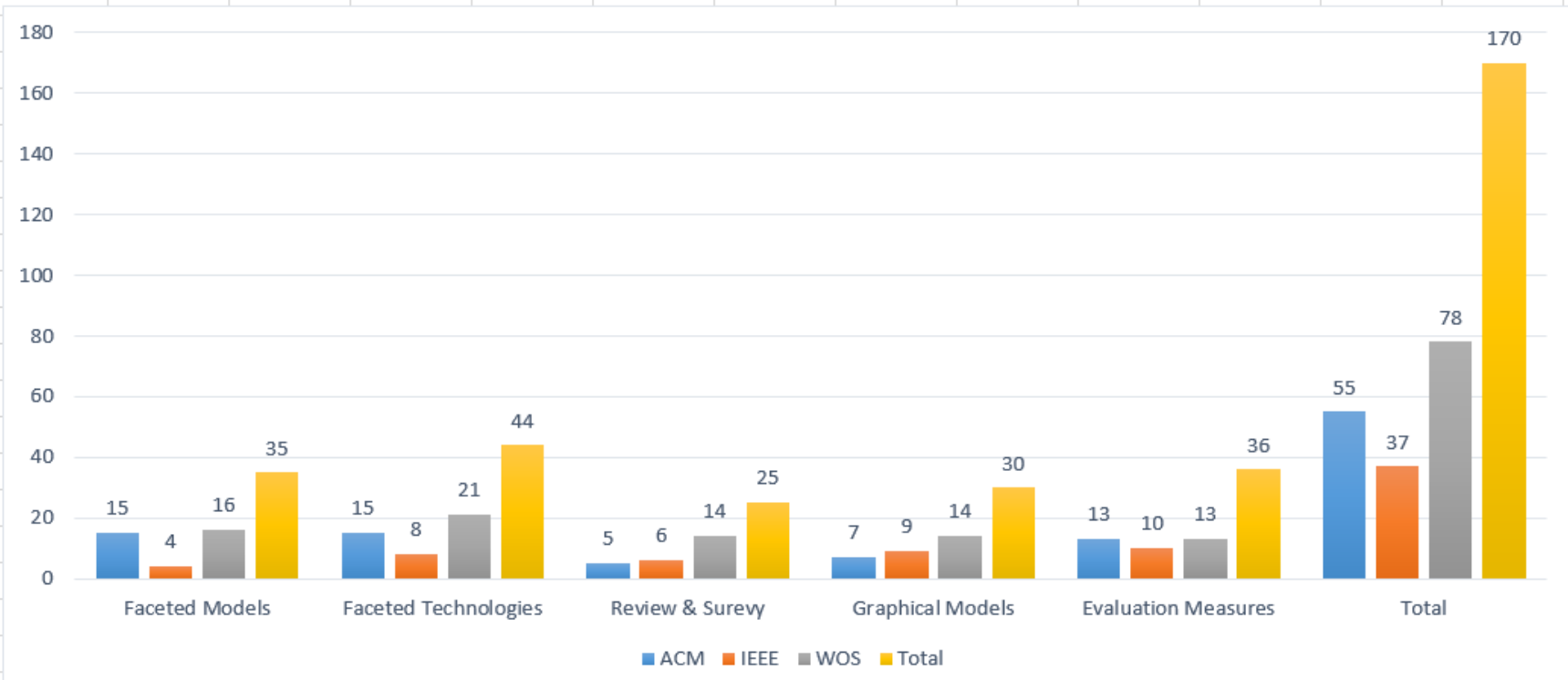

Figure 4. Articles categorized based on their contribution.

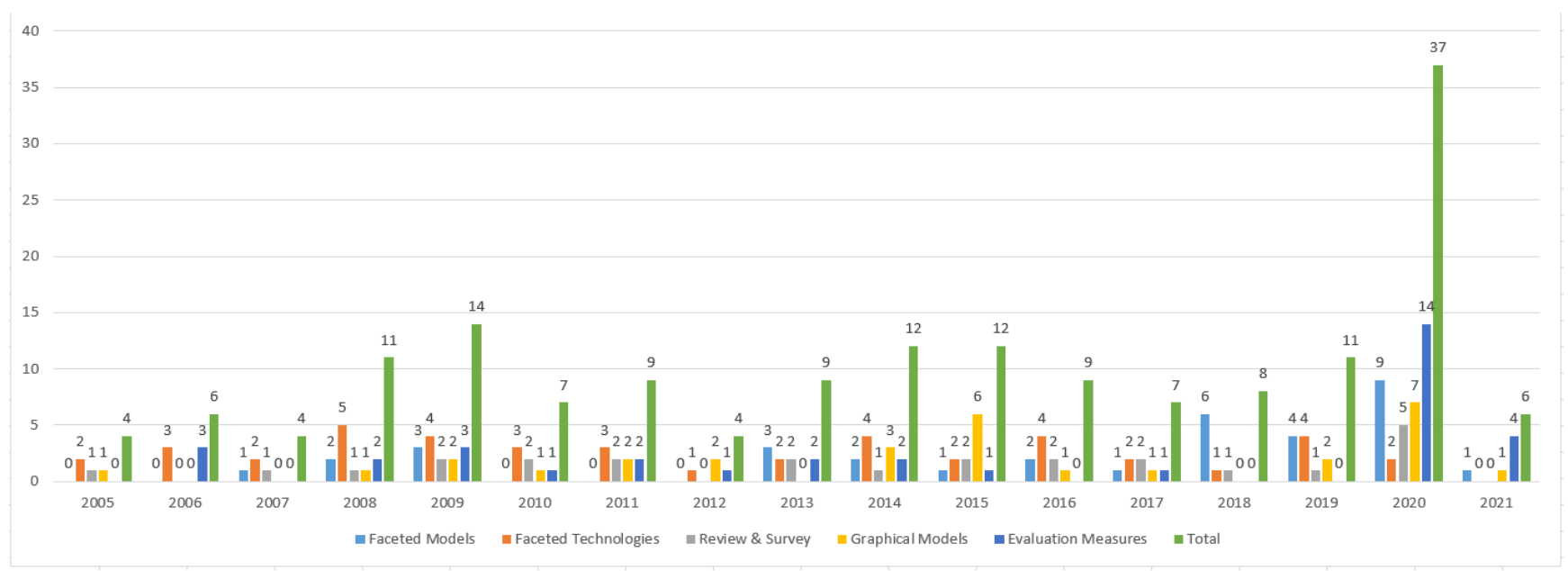

Figure 5. Articles published between 2005 and 2021.

\section{Taxonomy and Research of Faceted Search}

In view of comprehensive FS, which has been developed in recent years, we developed an FS taxonomy representation of the existing literature, as illustrated in Figure 6. The presented approach consisted of several facets, including essential techniques, evaluation measures, graphical models, and faceted models. Considering the facet model's characteristics, suitable terminologies that can be of good use are structure, interactivity, theoretical foundation, etc. Additionally, the facet was composed of precisely three keywords/terms: dynamic faceted, interface, and hierarchy. These coincided with the other stages. Subsequently, the matrices of the evaluation consisted of two subterms as follows: "subjective" and "objective", explaining the proposed system in detail with the help of a block diagram:

RQ1. What does the existing research literature reveal about the faceted search approach of web search service providers? 


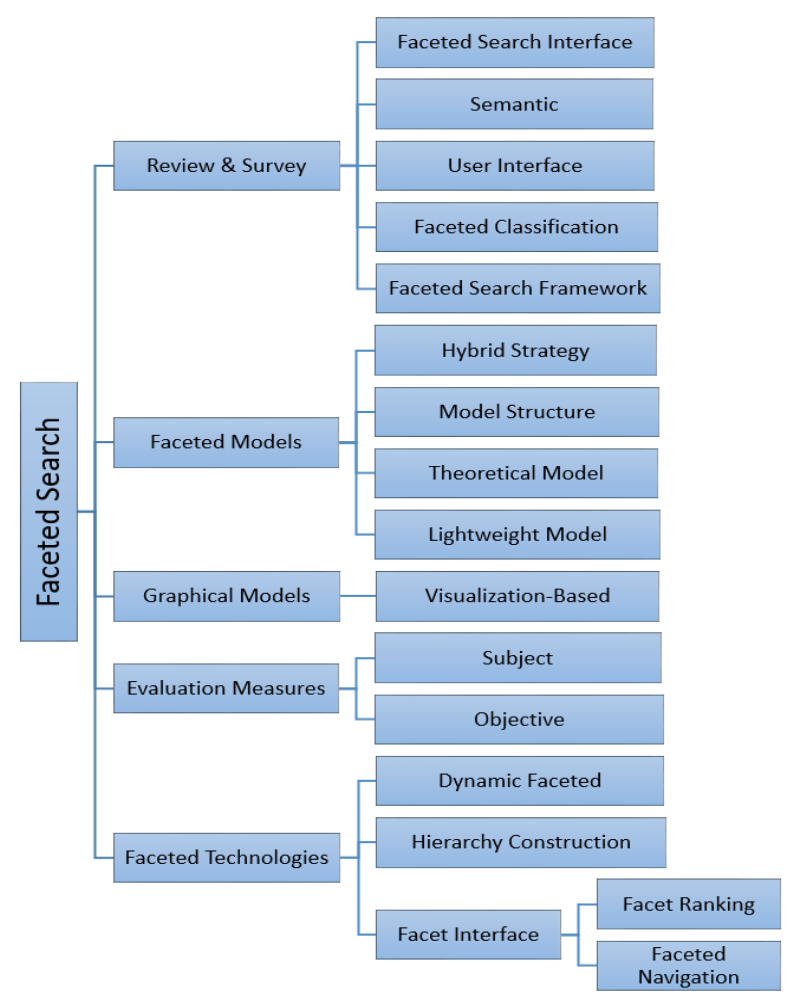

Figure 6. Taxonomy of faceted search.

\subsection{Survey and Review}

The current state-of-the-art FS and its applications are well described and summarized in the recently published survey and review articles. Three studies reviewed the technological challenges and concerns about FS $[8,23,24]$. The other 25 articles in this category were divided into four subcategories. The representative surveys of these studies on FS are summarized and discussed as follows:

1. FS interface: The papers in this subcategory investigated the framework or the platform model based on the prototype that will be developed. One paper [25] dissected the behavioral characteristics of ES and identified six tasks, namely: knowledge acquisition, comparison, planning, finding, answering, and navigating questions. These comparisons helped in evaluating the compatibility of this report and discovery on various sorting experiments;

2. Semantic FS and linked open data: The papers in this subcategory surveyed the most recent studies concerning RDF/S datasets and elaborated on the interaction of session-based approaches for ES. Three papers [26-28] focused on several aspects of these datasets, including the assumed target user, the configuration of the underlying information structure, and the generality and features of the browsing structure. The article [29] developed several evaluation models that adopted a user-centered ES method. The complexities and obstacles in ES were also discussed, as seen by the lack of strategies for evaluating ES models. One paper [30] proposed a comprehensive tutorial. This new information visualization mechanism can help users create informed design considerations about integrating information visualization into their interactive information search;

3. User interface: The papers under this category presented an improved user interface design for FS. Among the collected research articles, two papers [31,32] reviewed the concept of ES and its primary theoretical grounds and explained such a complex concept by demonstrating the context of its problem and its search procedure. They also predicted the direction of advancements in the ES area depending on the social state of information search. The authors of [9,33-36] studied the development of new decision support tools and explored the visual knowledge system. The main 
contribution of these studies was to find out how a system can achieve the intended enhancement based on the survey that was performed on the projects by using meta requirements. The authors argued that enterprise users in petroleum manufacturing, for instance, can help explore the SE results related to word repetition filters. Other collected studies presented an overview of FS. The research in the library of "futuregeneration" catalogs that combine FS outcomes was later evaluated based on the questions of what is known by now regarding FS and the way to design improved research for FS in library catalogs [37-41];

4. Faceted classification: These analyzed the interface that enables faster and easier access to the required information. The articles [42,43] discussed six main facets of searches: query sessions, space, user attitude, technical requirements, space of contents, and user racial background. They also presented an interface that enables smoother access to the required information, which illustrates the motivations and needs for FS. The lack of all organizations can further summarize the result of faster and easier access to all sorts of information;

5. Faceted search framework: The papers in this subcategory investigated visualizing browsing and refining search results to allow users to build complex search queries visually. This proposed FS can also solve the problem of lexical uncertainty in current search engines and result in greater user interest [44,45].

RQ2. What are the primary aims, vision, and trends for faceted search, and what research can be highlighted in this area?

\subsection{Faceted Model}

The second category included 35 related research articles. This category was divided into five subcategories as follows: hybrid strategy [46]; model structure [47,48]; formal concept analysis (FCA) [49]; lightweight ontology [50]; and partitioning [51]. These works were presented to improve the reachability of relevant information objects and user behavior. Moreover, this also improves the user searching process by implementing the activity of the data exchange category-theoretic model [52] and the Random Forest (RF) model [53]. The main facets that were presented here were (1) trees and (2) graphs. Both were obtained from the taxonomy of the faceted data structure. It is meaningful to mention that the former facet shows the data-structure-specific faceted taxonomy [54]. In Table 2, we briefly compare the facet models mentioned above by model structure, the main concepts, and other key aspects.

Table 2. Comparison of existing facet models.

\begin{tabular}{|c|c|c|c|c|c|c|c|}
\hline Ref & Time & Model & Data & Main Concepts & Structure & Ranking & $\begin{array}{l}\text { Improvement, A: Advantages, } \\
\text { D: Drawbacks }\end{array}$ \\
\hline [46] & 2017 & ES strategy & Web pages & $\begin{array}{l}\text { Automatically } \\
\text { selecting }\end{array}$ & $\begin{array}{l}\text { Facet extraction } \\
\text { Form-based } \\
\text { search }\end{array}$ & None & $\begin{array}{l}\text { Presented an ES approach that enables } \\
\text { users to differentiate all data efficiently. } \\
\text { A: minimizes the large and } \\
\text { overwhelming datasets into small and } \\
\text { precise information that is in line with } \\
\text { the user's interest. D: more tests are } \\
\text { needed. }\end{array}$ \\
\hline [47] & 2009 & $\begin{array}{c}\text { Driven and } \\
\text { domain-neutral } \\
\text { approach }\end{array}$ & $\begin{array}{l}\text { Real datasets } \\
\text { comprising } \\
\text { blog posts }\end{array}$ & $\begin{array}{c}\text { Manually selecting } \\
\text { attributes from the } \\
\text { database }\end{array}$ & Keyword search & $\begin{array}{l}\text { Relevance to a } \\
\text { search query }\end{array}$ & $\begin{array}{l}\text { Modern searching approaches that are } \\
\text { similar to FS, which allows progressive } \\
\text { improvements for query keywords. A: } \\
\text { enables enhanced data analysis and } \\
\text { searching models. D: manual browsing } \\
\text { is the only option to obtain results } \\
\text { without assistive query features. }\end{array}$ \\
\hline [51] & 2018 & $\begin{array}{l}\text { Distinguishes the } \\
\text { facet combinations } \\
\text { on spatial bases } \\
\text { through combining, } \\
\text { partitioning }\end{array}$ & Text mining & $\begin{array}{l}\text { Automatically select } \\
\text { based on information } \\
\text { extraction results }\end{array}$ & $\begin{array}{l}\text { Based on users' } \\
\text { selection }\end{array}$ & None & $\begin{array}{l}\text { The combinations of facets to } \\
\text { consequently enhance ordinary FS } \\
\text { through understanding the analysis, } \\
\text { which has important footprints in } \\
\text { spatial capacity. A: it has been upgraded } \\
\text { to a geo-visual analytics system by using } \\
\text { an easier and simpler user interface. D: } \\
\text { not possible to locate an advanced type } \\
\text { for exploring the FS literature. }\end{array}$ \\
\hline
\end{tabular}


Table 2. Cont

\begin{tabular}{|c|c|c|c|c|c|c|c|}
\hline Ref & Time & Model & Data & Main Concepts & Structure & Ranking & $\begin{array}{c}\text { Improvement, A: Advantages, } \\
\text { D: Drawbacks }\end{array}$ \\
\hline [52] & 2018 & Astera & $\begin{array}{l}\text { Joining the } \\
\text { attributes of } \\
\text { several } \\
\text { formats using } \\
\text { the FS } \\
\text { formulation }\end{array}$ & $\begin{array}{l}\text { Graph model and } \\
\text { semantic links to the } \\
\text { collection, } \\
\text { ImageCLEF from } \\
\text { Wikipedia }\end{array}$ & $\begin{array}{l}\text { It can solely be a } \\
\text { representation of } \\
\text { data if inherent } \\
\text { features are not } \\
\text { used }\end{array}$ & $\begin{array}{l}\text { Hybrid ranking } \\
\text { method }\end{array}$ & $\begin{array}{l}\text { Focused on the reachability analysis of } \\
\text { the collections of multimodal graphs. A: } \\
\text { how different facets and the types of } \\
\text { links affect the reachability of adequate } \\
\text { information objects. D: requires } \\
\text { increasing the semantic and similarity } \\
\text { links' effects to enhance the } \\
\text { graph reachability. }\end{array}$ \\
\hline [53] & 2019 & $\begin{array}{l}\text { Random Forest } \\
\text { (RF) approach }\end{array}$ & Text mining & $\begin{array}{l}\text { Query formulation } \\
\text { extraction results }\end{array}$ & $\begin{array}{l}\text { Use nodes to } \\
\text { automatically } \\
\text { generate queries } \\
\text { to the users }\end{array}$ & $\begin{array}{l}\text { Relevance to a } \\
\text { search query } \\
\text { keyword search }\end{array}$ & $\begin{array}{l}\text { The interactions of users in real time } \\
\text { was investigated from the perspective of } \\
\text { both human factors and data science, } \\
\text { respectively. A: the results in this work } \\
\text { are relevant in understanding the } \\
\text { searchers in order to present or improve } \\
\text { a practical model of FS. D: a high-quality } \\
\text { facet was selected while only one } \\
\text { university library was considered. }\end{array}$ \\
\hline [55] & 2019 & TogoGenome & $\begin{array}{l}\text { Genome } \\
\text { database }\end{array}$ & Semantic web-based & $\begin{array}{l}\text { Keyword } \\
\text { searches }\end{array}$ & None & $\begin{array}{l}\text { Presented a semantic FS approach by } \\
\text { gene functional annotation, taxonomy, } \\
\text { phenotypes, and environment based on } \\
\text { the related anthologies. A: Each module } \\
\text { in the pages is separately served as } \\
\text { TogoStanza, which is a generic } \\
\text { framework for rendering an information } \\
\text { block as IFRAME/web components. D: } \\
\text { users cannot edit and test these queries } \\
\text { for similar purposes with ease. }\end{array}$ \\
\hline [56] & 2019 & $\begin{array}{l}\text { FS system for Thai } \\
\text { research articles }\end{array}$ & $\begin{array}{l}\text { knowledge } \\
\text { extraction } \\
\text { from facets } \\
\text { and two-level } \\
\text { FS }\end{array}$ & $\begin{array}{l}\text { The FS system was } \\
\text { constructed based on } \\
\text { the Apache Solr SE }\end{array}$ & $\begin{array}{l}\text { Knowledge } \\
\text { discovery tool }\end{array}$ & $\begin{array}{l}\text { Real-time } \\
\text { metadata }\end{array}$ & $\begin{array}{l}\text { Provided the approach to the design and } \\
\text { implementation of a knowledge } \\
\text { discovery tool in terms of FS. A: system } \\
\text { design for FS is explained together with } \\
\text { data preparation. D: needs to work on } \\
\text { manually extracting the metadata from } \\
\text { all the datasets. }\end{array}$ \\
\hline [57] & 2019 & $\begin{array}{l}\text { Content-based } \\
\text { recommendation }\end{array}$ & $\begin{array}{l}\text { Records } \\
\text { collected of } \\
\text { Parliamentary } \\
\text { Proceedings }\end{array}$ & $\begin{array}{l}\text { Profile-based expert } \\
\text { recommendation and } \\
\text { document filtering }\end{array}$ & $\begin{array}{l}\text { Representing } \\
\text { profiles based on } \\
\text { different } \\
\text { information } \\
\text { sources and } \\
\text { expert finding }\end{array}$ & Recommendation & $\begin{array}{l}\text { Provided text clustering to automatically } \\
\text { build compound profiles of experts to } \\
\text { properly reflect the topics in which they } \\
\text { are usually interested. A: represented } \\
\text { using multifaceted profiles. D: tackling } \\
\text { the problem of how recommendations } \\
\text { and filtering problems would be affected } \\
\text { when experts are represented by } \\
\text { temporary profiles. }\end{array}$ \\
\hline [58] & 2019 & $\begin{array}{l}\text { Combines full-text } \\
\text { search with facets }\end{array}$ & $\begin{array}{l}\text { Metadata- } \\
\text { based } \\
\text { clustering }\end{array}$ & $\begin{array}{l}\text { Modeling user } \\
\text { interests to identify } \\
\text { the user interests and } \\
\text { investigate the } \\
\text { relation between } \\
\text { them }\end{array}$ & $\begin{array}{l}\text { Search behavior } \\
\text { is related to } \\
\text { specific parts } \\
\text { within the } \\
\text { collection }\end{array}$ & $\begin{array}{l}\text { Reranking of the } \\
\text { results by time }\end{array}$ & $\begin{array}{l}\text { Improved system support or refine } \\
\text { recommendations in interactive IR. A: a } \\
\text { typical digital library with a richly } \\
\text { annotated historical newspaper } \\
\text { collection and an FS interface. D: } \\
\text { requires further exploration of the users } \\
\text { interested in specific parts of the } \\
\text { collection to use different } \\
\text { search techniques. }\end{array}$ \\
\hline [59] & 2019 & $\begin{array}{l}\text { Utilizes the } \\
\text { bag-of-words } \\
\text { model to transform } \\
\text { visual feature into } \\
\text { a vector } \\
\text { representation }\end{array}$ & $\begin{array}{l}\text { Multimedia } \\
\text { databases } \\
\text { from the LSC } \\
\text { dataset }\end{array}$ & $\begin{array}{l}\text { FS lifelog system to a } \\
\text { VR-platform }\end{array}$ & $\begin{array}{l}\text { Extracting visual } \\
\text { features from the } \\
\text { image was } \\
\text { performed }\end{array}$ & $\begin{array}{l}\text { Ranked list of } \\
\text { images }\end{array}$ & $\begin{array}{l}\text { Provided a LifeSeeker interactive lifelog } \\
\text { SE. A: helps solve the lexical gap } \\
\text { between novice users and the concept } \\
\text { annotation tools employed for } \\
\text { annotating the collection. D: enhances } \\
\text { the free-text search system. }\end{array}$ \\
\hline [60] & 2016 & $\begin{array}{l}\text { Category-theoretic } \\
\text { model }\end{array}$ & $\begin{array}{l}\text { Database } \\
\text { schemas }\end{array}$ & $\begin{array}{l}\text { Automatically } \\
\text { selecting }\end{array}$ & $\begin{array}{l}\text { Natural } \\
\text { hierarchical } \\
\text { relationships, } \\
\text { form-based } \\
\text { search }\end{array}$ & $\begin{array}{l}\text { How many } \\
\text { occurrences }\end{array}$ & $\begin{array}{l}\text { Illustrated and enforced the fact that } \\
\text { facets browsing can be modeled by } \\
\text { category theory to enhance the } \\
\text { development of interfaces to integrate } \\
\text { several facets of browsing approaches. } \\
\text { A: describing the terminologies to } \\
\text { expand the approach can be utilized to } \\
\text { integrate the facets. D: recommended to } \\
\text { further investigate the visualization } \\
\text { impact in FS models such as DELVE } \\
\text { because several parts can be affected by } \\
\text { that interaction. }\end{array}$ \\
\hline
\end{tabular}


Table 2. Cont

\begin{tabular}{|c|c|c|c|c|c|c|c|}
\hline Ref & Time & Model & Data & Main Concepts & Structure & Ranking & $\begin{array}{c}\text { Improvement, A: Advantages, } \\
\text { D: Drawbacks }\end{array}$ \\
\hline [61] & 2018 & QDMiner & $\begin{array}{l}\text { Build two } \\
\text { datasets from } \\
\text { scratch }\end{array}$ & $\begin{array}{l}\text { Dynamically mine } \\
\text { the query text by } \\
\text { categorizing and } \\
\text { extracting repeatable } \\
\text { texts and repeat at the } \\
\text { top results }\end{array}$ & $\begin{array}{l}\text { Presents two } \\
\text { models, the } \\
\text { context similarity } \\
\text { model to arrange } \\
\text { the query facets } \\
\text { and the website } \\
\text { model }\end{array}$ & None & $\begin{array}{l}\text { Issues related to identifying the query } \\
\text { facets. These facets are found in } \\
\text { different categories and groups of texts } \\
\text { and phrases describing and } \\
\text { summarizing the query context. A: } \\
\text { finding enhanced query facets is } \\
\text { demonstrated by designing the } \\
\text { fine-grained parity between the repeated } \\
\text { lists. D: requires further exploration on } \\
\text { the output to improve the facets and } \\
\text { enhance the query extraction. }\end{array}$ \\
\hline$[62]$ & 2008 & FleXplorer & Web page & $\begin{array}{l}\text { Automatically select } \\
\text { based on the } \\
\text { information } \\
\text { extraction result }\end{array}$ & Subject hierarchy & $\begin{array}{l}\text { Preferences for } \\
\text { prestige, results' } \\
\text { selection, and } \\
\text { workload usage }\end{array}$ & $\begin{array}{l}\text { Proposes an authoritative approach that } \\
\text { obtains the faceted materialized } \\
\text { taxonomies. A: enables better control } \\
\text { over terms' taxonomies, objects, and } \\
\text { facets' description, e.g., modification } \\
\text { and deletion. D: expands the FleXplorer, } \\
\text { which is able to act as a mediator to } \\
\text { manage the information remotely. }\end{array}$ \\
\hline [63] & 2015 & $\begin{array}{c}\text { The theoretical } \\
\text { bases category is } \\
\text { used for FS }\end{array}$ & Text mining & $\begin{array}{l}\text { Automatically select } \\
\text { based on information } \\
\text { extraction results }\end{array}$ & $\begin{array}{l}\text { Uses nodes to } \\
\text { automatically } \\
\text { generate queries } \\
\text { to the users }\end{array}$ & None & $\begin{array}{l}\text { Directed towards the complexity of the } \\
\text { structure among the morphism } \\
\text { categories. A: utilizes the abstract } \\
\text { directories to produce the algorithms, } \\
\text { which are a model that can be applied } \\
\text { repeatedly. D: it requires containing } \\
\text { faceted ES phase models. Filters such as } \\
\text { zoom, filter, and overview will be } \\
\text { implemented. }\end{array}$ \\
\hline [64] & 2014 & eTACTS & $\begin{array}{l}\text { Data from the } \\
\text { pool of } \\
\text { participants }\end{array}$ & $\begin{array}{l}\text { Few facets were used } \\
\text { to index the resulting } \\
\text { trials whereby each } \\
\text { describes a unique } \\
\text { feature of the query } \\
\text { text; this enables a } \\
\text { user to choose the } \\
\text { facets to filter and } \\
\text { minimize the number } \\
\text { of results }\end{array}$ & $\begin{array}{l}\text { Arranged and } \\
\text { reordered them } \\
\text { based on the } \\
\text { initial search } \\
\text { rank }\end{array}$ & $\begin{array}{l}\text { Top ranked by } \\
\text { conventional SEs }\end{array}$ & $\begin{array}{l}\text { It digs out the consecutive tags of } \\
\text { eligibility obtained from the free-text } \\
\text { clinical trials to be utilized in indexing } \\
\text { them. A: (1) frequently minimizes the SE } \\
\text { results from more than a thousand trials } \\
\text { to approximately ten; (2) describes trials } \\
\text { that are randomly not top ranked by } \\
\text { typical SEs; (3) obtained a higher } \\
\text { number of perfect trials than } \\
\text { conventional SEs. D: (1) assessment of } \\
\text { the users mentioned by this work is } \\
\text { focused on showing the effectiveness of } \\
\text { an easy case study; (2) user assessment } \\
\text { is focused on a singular medical } \\
\text { condition, which describes the search of } \\
\text { the user. }\end{array}$ \\
\hline [65] & 2009 & FacetLens & $\begin{array}{l}\text { The } \\
\text { orientation } \\
\text { that links both } \\
\text { the dataset } \\
\text { and the facets }\end{array}$ & $\begin{array}{l}\text { Pivot operations to } \\
\text { enable users to have } \\
\text { easy navigation of the } \\
\text { facet dataset by } \\
\text { utilizing the } \\
\text { relationships that link } \\
\text { the items }\end{array}$ & $\begin{array}{l}\text { Metadata } \\
\text { structure }\end{array}$ & Rank criterion & $\begin{array}{l}\text { Define the interactive visualization } \\
\text { algorithm's efficiency in upholding the } \\
\text { understanding of the datasets within the } \\
\text { facets. A: facet relationships can be } \\
\text { improved and made clearer to enhance } \\
\text { the directivity by exploiting the coloring } \\
\text { and animation, timing, etc. D: requires } \\
\text { more accurate features that contribute to } \\
\text { enhancing the FacetLens } \\
\text { user experience. }\end{array}$ \\
\hline [66] & 2013 & MultiFacet & $\begin{array}{l}\text { An interface of } \\
\text { faceted } \\
\text { browsing to } \\
\text { uphold several } \\
\text { types of data }\end{array}$ & $\begin{array}{l}\text { Developed an FS } \\
\text { system, to expand the } \\
\text { current system of } \\
\text { faceted browsing }\end{array}$ & $\begin{array}{l}\text { The approach } \\
\text { builds facets for } \\
\text { graphics using } \\
\text { computer visual } \\
\text { techniques }\end{array}$ & None & $\begin{array}{l}\text { Features of MultiFacet provide glimpses } \\
\text { at the multimedia without defining the } \\
\text { type of media. A: (1) an approach that } \\
\text { enables facets' integration from texts, } \\
\text { graphics, etc.; (2) graphical facets are } \\
\text { constructed using low-level visual } \\
\text { attributes of these graphics. D: requires } \\
\text { embedding users to study to indicate the } \\
\text { efficiency of the MultiFacet interface. }\end{array}$ \\
\hline [67] & 2018 & Facetize & $\begin{array}{l}\text { Linked data, } \\
\text { publishing } \\
\text { method that } \\
\text { facilitates data } \\
\text { linking }\end{array}$ & $\begin{array}{l}\text { Contributes to users } \\
\text { with no specific } \\
\text { technical background } \\
\text { to purify the datasets } \\
\text { and transform them } \\
\text { into easily explorable } \\
\text { data }\end{array}$ & $\begin{array}{l}\text { Features of the } \\
\text { approach in the } \\
\text { context of the } \\
\text { verbal } \\
\text { communication } \\
\text { system and also } \\
\text { emerging }\end{array}$ & $\begin{array}{l}\text { Ranked based on } \\
\text { reference } \\
\text { focused objects }\end{array}$ & $\begin{array}{l}\text { Structure and the flow of facetizing an } \\
\text { editor that enables users to change the } \\
\text { datasets, either static or dynamic, to the } \\
\text { extent of it being fully explored } \\
\text { automatically or manually. A: various } \\
\text { tasks are supported by features such as } \\
\text { data deletion, editing, visibility, } \\
\text { selection, etc., which provides users a } \\
\text { friendly interface. D: approaches to } \\
\text { anticipate the lost data are not available. }\end{array}$ \\
\hline
\end{tabular}


Table 2. Cont

\begin{tabular}{|c|c|c|c|c|c|c|c|}
\hline Ref & Time & Model & Data & Main Concepts & Structure & Ranking & $\begin{array}{l}\text { Improvement, A: Advantages, } \\
\text { D: Drawbacks }\end{array}$ \\
\hline [68] & 2008 & FacetZoom & $\begin{array}{l}\text { Continuous } \\
\text { and discrete } \\
\text { datasets }\end{array}$ & $\begin{array}{l}\text { FacetZoom, a unique } \\
\text { widget that the joins } \\
\text { the browsing of facets } \\
\text { with the expandable } \\
\text { user interface }\end{array}$ & $\begin{array}{l}\text { Hierarchical } \\
\text { facets are } \\
\text { space-filling } \\
\text { widgets to } \\
\text { enable quick } \\
\text { traversal in all } \\
\text { stages and } \\
\text { maintain the } \\
\text { context }\end{array}$ & None & $\begin{array}{l}\text { The space-structuring widgets and data } \\
\text { are applied and sampled, respectively, } \\
\text { using the two prototypes. A: } \\
\text { multilateral and enables static search } \\
\text { and browsing features in the diversity of } \\
\text { application settings. D: needs to } \\
\text { differentiate between the performance of } \\
\text { all widgets to different techniques. }\end{array}$ \\
\hline [69] & 2017 & $\begin{array}{l}\text { Object property } \\
\text { framework }\end{array}$ & $\begin{array}{l}\text { Datasets of } \\
\text { DBpedia, } \\
\text { LOD, and } \\
\text { YAGO2 }\end{array}$ & $\begin{array}{l}\text { Proposed techniques } \\
\text { of purifying the } \\
\text { subtaxonomy while } \\
\text { upholding two } \\
\text { experiments to } \\
\text { enforce the } \\
\text { outstanding } \\
\text { performance in terms } \\
\text { of effectiveness and } \\
\text { efficiency }\end{array}$ & $\begin{array}{l}\text { Inheritance } \\
\text { Richness (IR) to } \\
\text { intrude the } \\
\text { subtaxonomy } \\
\text { structure }\end{array}$ & None & $\begin{array}{l}\text { Establishes a faceted taxonomy to } \\
\text { arrange the heterogeneous facilities, } \\
\text { allow the different categories of facilities } \\
\text { using the subtaxonomies, and uphold } \\
\text { the FS navigation for related } \\
\text { information applications. A: framework } \\
\text { in which the facets are described using } \\
\text { an object feature to extract the relevant } \\
\text { data; also contributes to creating the } \\
\text { concept taxonomy-generation algorithm. } \\
\text { D: (1) several legacies exist in } \\
\text { subtaxonomies; (2) it is difficult to } \\
\text { realize and understand the concept } \\
\text { hierarchies; (3) the identification of } \\
\text { entities and its mapping should be } \\
\text { realized in generating the taxonomies. }\end{array}$ \\
\hline [70] & 2019 & $\begin{array}{l}\text { Multifaceted Trust } \\
\text { Model }\end{array}$ & $\begin{array}{l}\text { (1) Yelp, (2) } \\
\text { LibraryThing }\end{array}$ & $\begin{array}{l}\text { Yelp, Booking, } \\
\text { Expedia, and } \\
\text { LibraryThing } \\
\text { provided by social } \\
\text { networks }\end{array}$ & $\begin{array}{l}\text { Finding general } \\
\text { classes of data in } \\
\text { order to create } \\
\text { models } \\
\text { applicable to } \\
\text { different case } \\
\text { studies }\end{array}$ & None & $\begin{array}{l}\text { Multifaceted trust model to integrate } \\
\text { local trust, represented by social links, } \\
\text { with various types of global trust } \\
\text { evidence provided by social networks. } \\
\text { A: integrated into collaborative filtering; } \\
\text { the resulting system was tested on two } \\
\text { public datasets. D: need to evaluate the } \\
\text { model on different datasets. }\end{array}$ \\
\hline [71] & 2020 & COVIDSeer & $\begin{array}{l}\text { CORD-19 } \\
\text { Dataset }\end{array}$ & $\begin{array}{l}\text { Uses CeKE-TA, } \\
\text { which uses only the } \\
\text { title and abstract }\end{array}$ & $\begin{array}{l}\text { Uses a } \\
\text { combination of } \\
\text { title, abstract, } \\
\text { and available } \\
\text { full-texts }\end{array}$ & None & $\begin{array}{l}\text { Built and integrated a filtering } \\
\text { mechanism for further accessing the } \\
\text { results of a query of interest. A: Allows } \\
\text { users to select filters from one or } \\
\text { multiple categories; the intersection of } \\
\text { all is presented in the search results. D: } \\
\text { implements author name } \\
\text { disambiguation so as to correctly } \\
\text { associate every author to his/her } \\
\text { research paper. }\end{array}$ \\
\hline [72] & 2021 & XNLP & $\begin{array}{l}\text { Metadata } \\
\text { structure }\end{array}$ & $\begin{array}{c}\text { Interactive } \\
\text { browser-based } \\
\text { system embodying a } \\
\text { living survey }\end{array}$ & $\begin{array}{l}\text { Keyword search } \\
\text { matches }\end{array}$ & None & $\begin{array}{l}\text { Interactive browser-based system } \\
\text { embodying a living survey of recent } \\
\text { research in the field of Explainable AI } \\
\text { (XAI) within the domain of Natural } \\
\text { Language Processing (NLP). D: aware of } \\
\text { other papers that should be included. }\end{array}$ \\
\hline [73] & 2020 & SAUCE & $\begin{array}{l}\text { Lexical } \\
\text { Database }\end{array}$ & $\begin{array}{l}\text { Allows artists to find } \\
\text { different types of } \\
\text { assets in different } \\
\text { ways depending on } \\
\text { personal preference }\end{array}$ & $\begin{array}{l}\text { Indexing of text } \\
\text { and language } \\
\text { structures }\end{array}$ & None & $\begin{array}{l}\text { Discusses some of the requirements of } \\
\text { modern asset storage systems for VFX } \\
\text { and animation. A: introduces two } \\
\text { systems that were built to address these } \\
\text { challenges as part of the collaborative } \\
\text { EU funded "SAUCE" project; DNEG's } \\
\text { search and retrieval framework and } \\
\text { Foundry's back-end asset storage. }\end{array}$ \\
\hline [74] & 2020 & DeepHate & $\begin{array}{l}\text { Latent repre- } \\
\text { sentations }\end{array}$ & $\begin{array}{l}\text { Deep learning model } \\
\text { that combines } \\
\text { multifaceted text } \\
\text { representations such } \\
\text { as word embeddings }\end{array}$ & $\begin{array}{l}\text { Real-world } \\
\text { datasets }\end{array}$ & None & $\begin{array}{l}\text { Deep learning framework known as } \\
\text { DeepHate, which utilizes multifaceted } \\
\text { text representations for automatic hate } \\
\text { speech detection. A: evaluated } \\
\text { DeepHate on three publicly available } \\
\text { real-world datasets; extensive } \\
\text { experiments showed that DeepHate } \\
\text { outperformed the state-of-the-art } \\
\text { baselines. D: incorporating nontextual } \\
\text { features into the DeepHate model and } \\
\text { improving the posts' sentiment and } \\
\text { topic representations with more } \\
\text { advanced techniques. }\end{array}$ \\
\hline
\end{tabular}


Table 2. Cont.

\begin{tabular}{|c|c|c|c|c|c|c|c|}
\hline Ref & Time & Model & Data & Main Concepts & Structure & Ranking & $\begin{array}{l}\text { Improvement, A: Advantages, } \\
\text { D: Drawbacks }\end{array}$ \\
\hline [75] & 2020 & $\begin{array}{l}\text { Newspaper } \\
\text { Navigator }\end{array}$ & $\begin{array}{l}\text { Examples of } \\
\text { searching }\end{array}$ & $\begin{array}{l}\text { Open faceted search, } \\
\text { which empowers } \\
\text { users to specify their } \\
\text { own facets in an open } \\
\text { domain fashion }\end{array}$ & $\begin{array}{l}\text { Users need to } \\
\text { knowhow to } \\
\text { define and refine } \\
\text { facets }\end{array}$ & None & $\begin{array}{l}\text { Walks through examples of searching } \\
\text { with Newspaper Navigator and } \\
\text { highlights the facet learning and } \\
\text { exploration affordances. D: Facet } \\
\text { categories must be predefined and may } \\
\text { not align with the facets that a user } \\
\text { desires during the search process. }\end{array}$ \\
\hline [1] & 2020 & $\begin{array}{c}\text { Data lake } \\
\text { organization }\end{array}$ & $\begin{array}{l}\text { Proposes an } \\
\text { approximate } \\
\text { algorithm }\end{array}$ & $\begin{array}{l}\text { For the data lake } \\
\text { organization problem }\end{array}$ & $\begin{array}{c}\text { Structures } \\
\text { optimized for } \\
\text { dataset } \\
\text { discovery }\end{array}$ & $\begin{array}{l}\text { Participants' } \\
\text { rankings }\end{array}$ & $\begin{array}{l}\text { Probabilistic model of how users } \\
\text { interact with an organization; proposes } \\
\text { an approximate algorithm for the data } \\
\text { lake organization problem. D: plans to } \\
\text { compare organizations with existing } \\
\text { taxonomies and to provide techniques } \\
\text { for metadata enrichment. }\end{array}$ \\
\hline [76] & 2020 & $\begin{array}{l}\text { Simulation-based } \\
\text { evaluation }\end{array}$ & $\begin{array}{l}\text { Size and the } \\
\text { granularity of } \\
\text { the sought } \\
\text { object ranking }\end{array}$ & $\begin{array}{l}\text { Extension of the } \\
\text { model with two } \\
\text { parameters that } \\
\text { enable specifying the } \\
\text { desired answer }\end{array}$ & Structured query & $\begin{array}{l}\text { The Smartfsrank } \\
\text { ranking }\end{array}$ & $\begin{array}{l}\text { Extended model for FS that aims at } \\
\text { improving the exploration experience of } \\
\text { the users. Proposed two parameters that } \\
\text { specify the desired properties of the } \\
\text { returned answers. Investigated indexes } \\
\text { and algorithms for scalability, i.e., for } \\
\text { enabling faceted search with automated } \\
\text { ranking over very big datasets. }\end{array}$ \\
\hline [77] & 2020 & LINDASearch & $\begin{array}{l}\text { Open Linked } \\
\text { datasets }\end{array}$ & $\begin{array}{l}\text { Semantic search, } \\
\text { faceted navigation, } \\
\text { data unification, } \\
\text { discovering, and } \\
\text { generation of search } \\
\text { recommendations } \\
\text { over the information } \\
\text { contained }\end{array}$ & Semantic Web & $\begin{array}{l}\text { Key ranking } \\
\text { techniques }\end{array}$ & $\begin{array}{l}\text { Linked data principles and practices to } \\
\text { be adopted by an increasing number of } \\
\text { data providers, which leads to the } \\
\text { creation of a global data space on the } \\
\text { web. LINDASearch is a system for } \\
\text { semantic search, faceted navigation, } \\
\text { data unification, discovering, and } \\
\text { generation of search recommendation } \\
\text { over the information contained in the } \\
\text { Open Linked datasets available in the } \\
\text { web of data. Limitations to search } \\
\text { through datasets from multiple } \\
\text { domains. }\end{array}$ \\
\hline [78] & 2020 & SPARQL engines & RDF dataset & $\begin{array}{l}\text { Presents a } \\
\text { schema-agnostic } \\
\text { faceted browsing } \\
\text { benchmark } \\
\text { generation } \\
\text { framework for RDF } \\
\text { data and SPARQL } \\
\text { engines }\end{array}$ & Similarity-based & None & $\begin{array}{l}\text { Framework comes with an intermediate } \\
\text { domain-specific language. Thereby, the } \\
\text { approach is SPARQL-driven, which } \\
\text { means that every faceted search } \\
\text { information need is intentionally } \\
\text { expressed as a single SPARQL query. } \\
\text { Presented a schema-agnostic faceted } \\
\text { search benchmark generation } \\
\text { framework for triple stores. Comparison } \\
\text { of the generated benchmarks with } \\
\text { existing SPARQL-driven benchmarks in } \\
\text { order to provide a bigger picture such as } \\
\text { by means of assessing the similarities } \\
\text { and differences of benchmarks w.r.t. the } \\
\text { SPARQL language features used. }\end{array}$ \\
\hline [79] & 2014 & Hippalus & Small dataset & $\begin{array}{l}\text { Described and } \\
\text { evaluated Hippalus, a } \\
\text { system that offers } \\
\text { exploratory search } \\
\text { enriched with } \\
\text { preferences }\end{array}$ & $\begin{array}{l}\text { Faceted and } \\
\text { dynamic } \\
\text { taxonomies }\end{array}$ & $\begin{array}{l}\text { Preference- } \\
\text { ranked } \\
\text { list }\end{array}$ & $\begin{array}{l}\text { Hippalus supports the very popular } \\
\text { interaction model of Faceted and } \\
\text { Dynamic Taxonomies (FDT), enriched } \\
\text { with user actions, which allow the users } \\
\text { to express their preferences. The } \\
\text { Hippalus system demonstrates the } \\
\text { feasibility of this extension. }\end{array}$ \\
\hline
\end{tabular}

\subsection{Graphical Models}

These platforms can provide the information in audio format and graphics, such that it is no longer isolated. Therefore, it is said that they are occasionally connected through the metadata and semantic links, which poses several challenges in the retrieval of graphbased information. Subsequently, the focus of this research shows the important challenges faced when interacting with multiple data types and modalities, whereby each comes with unique intrinsic features and retrieval approaches.

The thirty articles in this category were inquiries ranging from migrating graphics and text to the advanced fusion of several approaches receiving considerable attention in the past few years [80-82]. The original or the subsets of data sources collected using the 
IR system can be visually illustrated to help users better use it. These techniques can either operate together or separately to improve system performance [83].

The visual illustration of data can contribute to decision making, information delivery, and data analysis. Nevertheless, this includes minimal interactivity-related data [84]. Therefore, it is advised that it should contain an adequate interactive interface to be more understandable, easy-to-use, approachable, and meaningful. Moreover, accessing the data is becoming relatively difficult when the amount of data grows rapidly. Hence, visualization techniques help users obtain better results from a large dataset [85]. It is noteworthy that facets do not convey much information when using visualization [86-90]. In Table 3, we briefly compare the visualization techniques based on their data collection approaches, the faceted methods used, and the ranking improvement, identifying the advantage and drawbacks of each.

Table 3. Comparison of existing facet graphical models.

\begin{tabular}{|c|c|c|c|c|c|c|}
\hline Ref & Model & Framework & Data Collection & Faceted Used & Ranking & $\begin{array}{l}\text { Improvement, A: Advantages, } \\
\text { D: Drawbacks }\end{array}$ \\
\hline [89] & $\begin{array}{l}\text { Knowminer } \\
\text { search }\end{array}$ & $\begin{array}{c}\text { FS model, extended by } \\
\text { interactive } \\
\text { visualizations that } \\
\text { allow users to analyze } \\
\text { various elements of } \\
\text { the consequence set }\end{array}$ & $\begin{array}{l}\text { Presents a visually } \\
\text { supported FS } \\
\text { interface; Apache } \\
\text { Lucene SE is the } \\
\text { backend of the } \\
\text { search solution }\end{array}$ & $\begin{array}{c}\text { Allows } \\
\text { functionality for } \\
\text { organizing } \\
\text { interesting } \\
\text { portfolio search } \\
\text { outcomes and } \\
\text { promotes social } \\
\text { characteristics for } \\
\text { rating and } \\
\text { boosting SE } \\
\text { outcomes }\end{array}$ & None & $\begin{array}{l}\text { Search interface allows both search kinds. } \\
\text { An FS interface allows the search outcome } \\
\text { set to be effectively narrowed down. A: the } \\
\text { visualization of entities and records in } \\
\text { distinct situations: (i) the geo-visualization } \\
\text { shows the distribution of extracted } \\
\text { geo-references; (ii) the display of trends } \\
\text { and correlations between facets; (iii) the } \\
\text { visualization of graphs allows the } \\
\text { exploration of relations between entities } \\
\text { and records; (iv) the data landscape } \\
\text { provides an overview of the search result } \\
\text { set's topical structure. D: need to extend } \\
\text { portfolio features, for instance by } \\
\text { automatically applying portfolio } \\
\text { suggestions for SE results, offering } \\
\text { sophisticated search using a portfolio as a } \\
\text { query seed. }\end{array}$ \\
\hline [90] & PivotPaths & $\begin{array}{l}\text { Showcases PivotPaths, } \\
\text { as an interactive } \\
\text { visualization to search } \\
\text { the resources of } \\
\text { faceted data }\end{array}$ & $\begin{array}{l}\text { Selected the Internet } \\
\text { Movie Database's } \\
\text { top-grossing films } \\
\text { and retrieved film } \\
\text { information from } \\
\text { the Rotten Tomatoes } \\
\text { film rating page }\end{array}$ & $\begin{array}{l}\text { Interface was } \\
\text { intended to allow } \\
\text { big collections to } \\
\text { be traversed } \\
\text { casually in an } \\
\text { aesthetically } \\
\text { pleasing way, } \\
\text { encouraging } \\
\text { exploration }\end{array}$ & $\begin{array}{l}\text { Showcases a } \\
\text { visualization } \\
\text { canvas that } \\
\text { reorders facet } \\
\text { values and spatial } \\
\text { data resources }\end{array}$ & $\begin{array}{l}\text { Supports pivoting operations as } \\
\text { lightweight techniques of interaction that } \\
\text { trigger gradual transitions between views } \\
\text { A: shared the results of the iterative } \\
\text { design-and-evaluation method, which } \\
\text { included semistructured interviews and the } \\
\text { implementation proposed for a big } \\
\text { academic publication database. D: } \\
\text { improves the experience of strolling and } \\
\text { obtains clearer knowledge of how } \\
\text { exploratory and casual navigation styles } \\
\text { can be supported. }\end{array}$ \\
\hline [91] & DEEPEYE & $\begin{array}{l}\text { Based on visualization } \\
\text { by examples, } \\
\text { automatically } \\
\text { recommends and } \\
\text { generates } \\
\text { visualizations }\end{array}$ & $\begin{array}{l}\text { Visualization use } \\
\text { cases and real- } \\
\text { world datasets }\end{array}$ & $\begin{array}{c}\text { Provides } \\
\text { keyword searches } \\
\text { and FS }\end{array}$ & $\begin{array}{l}\text { Graph-based } \\
\text { approach }\end{array}$ & $\begin{array}{l}\text { Presented visualization recognition } \\
\text { techniques to decide which visualizations } \\
\text { are meaningful and visualization ranking } \\
\text { techniques to rank the visualizations. A: } \\
\text { gives the user the keyword search and } \\
\text { allows click-based FS. D: difficult to steer; } \\
\text { has keyword search and FS. }\end{array}$ \\
\hline [92] & $\begin{array}{l}\text { Versatile } \\
\text { timeline tool }\end{array}$ & $\begin{array}{l}\text { Allows the user to } \\
\text { explore relations } \\
\text { between laboratory } \\
\text { values and a } \\
\text { multitude of } \\
\text { diagnoses }\end{array}$ & $\begin{array}{l}\text { Clinical research } \\
\text { database }\end{array}$ & $\begin{array}{c}\text { Developed a user } \\
\text { interface for FS } \\
\text { based on the Solr } \\
\text { SE }\end{array}$ & None & $\begin{array}{l}\text { Presented an integrated decision support } \\
\text { system FS and information visualization } \\
\text { based on textual information extraction. A: } \\
\text { the use case of mammography featured an } \\
\text { adapted FS application on the results of an } \\
\text { adapted information extraction pipeline. D: } \\
\text { required more user control of the } \\
\text { information extraction process. }\end{array}$ \\
\hline [93] & $\begin{array}{l}\text { FS information } \\
\text { exploration } \\
\text { model }\end{array}$ & $\begin{array}{l}\text { Geographical } \\
\text { knowledge of } \\
\text { semantic } \\
\text { representation for the } \\
\text { exploration of IR from } \\
\text { heterogeneous data }\end{array}$ & $\begin{array}{l}\text { Noisy datasets; data } \\
\text { exploration issparse }\end{array}$ & $\begin{array}{l}\text { Supports faceted } \\
\text { exploration; } \\
\text { model based on } \\
\text { transparency } \\
\text { sliders }\end{array}$ & Ranked list & $\begin{array}{l}\text { FS supporting a flexible visualization of } \\
\text { heterogeneous geographic data. A: graphical } \\
\text { representation of the search context using } \\
\text { alternative types of widget that support } \\
\text { interactive data visualization. D: model only } \\
\text { supports the specification of hard } \\
\text { visualization constraints on facet values. }\end{array}$ \\
\hline
\end{tabular}


Table 3. Cont.

\begin{tabular}{|c|c|c|c|c|c|c|}
\hline Ref & Model & Framework & Data Collection & Faceted Used & Ranking & $\begin{array}{c}\text { Improvement, A: Advantages, } \\
\text { D: Drawbacks }\end{array}$ \\
\hline [94] & $\begin{array}{l}\text { The Lifelog } \\
\text { Search } \\
\text { Challenge } \\
\text { (LSC) }\end{array}$ & $\begin{array}{l}\text { Interactive retrieval } \\
\text { from multimodal } \\
\text { lifelogs }\end{array}$ & $\begin{array}{l}\text { LSC'20 datasets; the } \\
\text { metadata provided } \\
\text { can be split into } \\
\text { four categories: } \\
\text { location, time, } \\
\text { activities, and } \\
\text { visual concepts }\end{array}$ & $\begin{array}{l}\text { Searching system } \\
\text { ranging from } \\
\text { faceted windows } \\
\text { in virtual reality }\end{array}$ & $\begin{array}{c}\text { Ranking } \\
\text { documents based } \\
\text { on visual features }\end{array}$ & $\begin{array}{l}\text { Built to address three crucial challenges, } \\
\text { which are accurate searching, fast } \\
\text { processing, and straightforward. A: } \\
\text { supports querying sequential moments and } \\
\text { visualizing the movements between them } \\
\text { on the map. This map can work as a } \\
\text { filtering option also. D: need to utilize all } \\
\text { given elements in the dataset;, visual } \\
\text { similarity retrieving is also intriguing. }\end{array}$ \\
\hline [95] & $\begin{array}{c}\text { Online } \\
\text { communities }\end{array}$ & $\begin{array}{l}\text { Online communities' } \\
\text { GUI designers }\end{array}$ & $\begin{array}{l}\text { Automated GUI } \\
\text { exploration to } \\
\text { collect data }\end{array}$ & $\begin{array}{l}\text { The component } \\
\text { height and width } \\
\text { in a scatter plot }\end{array}$ & $\begin{array}{c}\text { Ranking } \\
\text { mechanism based } \\
\text { on time }\end{array}$ & $\begin{array}{l}\text { GUI designers share their design artwork } \\
\text { and learn from each other. A: designers } \\
\text { collect, analyze, search, summarize, and } \\
\text { compare GUI designs on a massive scale. D: } \\
\text { requires the crowdsourcing method to filter } \\
\text { out apps with low-quality UI design. }\end{array}$ \\
\hline [96] & Facet graphs & $\begin{array}{c}\text { Achieves related } \\
\text { semantic data's } \\
\text { graph-based structure }\end{array}$ & $\begin{array}{l}\text { Consists of a group } \\
\text { of nodes that are } \\
\text { marked by semantic } \\
\text { nodes' relationships }\end{array}$ & $\begin{array}{c}\text { FS and combines } \\
\text { it with a } \\
\text { visualization }\end{array}$ & None & $\begin{array}{l}\text { Technique and instrument, which enables } \\
\text { people to more effectively access and } \\
\text { explore Semantic Web information, } \\
\text { leveraging semantic data's particular } \\
\text { features. A: the strategy uses the FS idea } \\
\text { and combines it with a visualization that } \\
\text { takes advantage of the graph-based } \\
\text { structure of related semantic data. D: } \\
\text { integration of suitable zooming } \\
\text { functionality in conjunction with a focus } \\
\text { and context method to encourage users to } \\
\text { maintain an overview even when using } \\
\text { huge facet sizes in a single graph. }\end{array}$ \\
\hline [97] & PFSgeo & $\begin{array}{l}\text { Geographical map } \\
\text { input to imply that } \\
\text { focus is restricted; } \\
\text { preferences are defend }\end{array}$ & Geographical data & $\begin{array}{c}\text { Preference- } \\
\text { enriched FS for } \\
\text { geographical data }\end{array}$ & $\begin{array}{l}\text { Ranking of } \\
\text { spatial data }\end{array}$ & $\begin{array}{l}\text { ES process, in particular the } \\
\text { Preference-enriched FS (PFS) process. A: } \\
\text { enhanced to explore datasets that also } \\
\text { contain geographical information. D: tiny } \\
\text { dataset of } 20 \text { hotels only. }\end{array}$ \\
\hline [98] & $\begin{array}{l}\quad \text { Based } \\
\text { browsing } \\
\text { paradigm and } \\
\text { a web browser } \\
\text { extension } \\
\text { companion }\end{array}$ & $\begin{array}{l}\text { Users traverse } \\
\text { graph-based data }\end{array}$ & Data web & $\begin{array}{c}\text { Typical FS } \\
\text { interface such as } \\
\text { Internet catalog } \\
\text { browsing }\end{array}$ & None & $\begin{array}{l}\text { It is necessary to update the web browsing } \\
\text { paradigm of one web page at a time } \\
\text { because the typical unit of web information } \\
\text { to interact with will no longer be an entire } \\
\text { web page. A: lower data bits and countless } \\
\text { data bits. D: needs to formulate complex } \\
\text { structured queries. }\end{array}$ \\
\hline [99] & NeSim & $\begin{array}{l}\text { Multifaceted graph, } \\
\text { graph-clustering } \\
\text { algorithms }\end{array}$ & $\begin{array}{l}\text { Facet is a group of } \\
\text { features that } \\
\text { emulate the } \\
\text { relationships } \\
\text { among the nodes in } \\
\text { a specific context }\end{array}$ & $\begin{array}{l}\text { Google Publisher } \\
\text { Dataset }\end{array}$ & None & $\begin{array}{l}\text { Optimizations to improve the scalability, } \\
\text { efficiency, and quality of the clusters. A: } \\
\text { addresses the problem of finding } \\
\text { communities from multifaceted graphs. D: } \\
\text { finding subgraphs with specific link } \\
\text { topologies; the problem of merging results } \\
\text { from several community discovery } \\
\text { algorithms on a single graph. }\end{array}$ \\
\hline [100] & Hōpara & $\begin{array}{l}\text { Information } \\
\text { visualization }\end{array}$ & Wikipedia web site & $\begin{array}{c}\text { Facets of } \\
\text { visualization }\end{array}$ & $\begin{array}{l}\text { The total strength } \\
\text { ranks them }\end{array}$ & $\begin{array}{l}\text { To make it simpler to explore Wikipedia. A: } \\
\text { abstracting from the content of the } \\
\text { document and enabling users to navigate } \\
\text { the resource at a greater level. D: cannot } \\
\text { provide conclusive, objective evidence of } \\
\text { the usefulness of Hōpara; only the } \\
\text { subjective emotions of customers about it. }\end{array}$ \\
\hline [101] & VisGets & $\begin{array}{c}\text { Visualization of data } \\
\text { widgets that } \\
\text { manipulate a web } \\
\text { query }\end{array}$ & Web browser & $\begin{array}{l}\text { Coordinated } \\
\text { opinions can } \\
\text { provide a deeper } \\
\text { understanding of } \\
\text { the dimensions of } \\
\text { these facets }\end{array}$ & $\begin{array}{c}\text { Ranking } \\
\text { mechanism based } \\
\text { on relevancy }\end{array}$ & $\begin{array}{l}\text { Researched how coordinated visualizations } \\
\text { could improve the search and exploration } \\
\text { of WWW information by facilitating the } \\
\text { formulation of these kinds of queries. A: } \\
\text { provides visual overviews of web assets to } \\
\text { the information seeker and provides a } \\
\text { means of visually filtering the data and } \\
\text { facilitating the development of dynamic SE } \\
\text { queries combining filters from more than } \\
\text { one data dimension. D: to know more } \\
\text { about the potential role of interactive } \\
\text { visualizations in searching for data, } \\
\text { considers additional data spaces and } \\
\text { formats beyond RSS as fresh VisGets kinds. }\end{array}$ \\
\hline
\end{tabular}


Table 3. Cont

\begin{tabular}{|c|c|c|c|c|c|c|}
\hline Ref & Model & Framework & Data Collection & Faceted Used & Ranking & $\begin{array}{c}\text { Improvement, A: Advantages, } \\
\text { D: Drawbacks }\end{array}$ \\
\hline [102] & $\begin{array}{l}\text { Visual search } \\
\text { interfaces, } \\
\text { information } \\
\text { visualization }\end{array}$ & $\begin{array}{l}\text { Fuzzy filtering idea } \\
\text { proved convenient to } \\
\text { solve comparative } \\
\text { tasks, but also } \\
\text { confused some } \\
\text { searchers who tried to } \\
\text { fix a search } \\
\text { assignment }\end{array}$ & $\begin{array}{l}\text { Financial products } \\
\text { dataset }\end{array}$ & $\begin{array}{l}\text { Feature used to } \\
\text { reduce the result } \\
\text { set was the facet } \\
\text { filter, whereas } \\
\text { less frequently, } \\
\text { the fuzzy filter } \\
\text { was used }\end{array}$ & None & $\begin{array}{l}\text { Presented an interface notion that enables } \\
\text { multiple product search, analysis, and } \\
\text { comparison approaches beginning with a } \\
\text { single product or summarizing the entire } \\
\text { information set. A: the idea is based on two } \\
\text { methods of visualization that enable } \\
\text { multidimensional information to be } \\
\text { represented across a set of parallel axes: } \\
\text { parallel coordinates and parallel sets. D: } \\
\text { needed for each axis to spread junctions; } \\
\text { class internal rearrangement of these } \\
\text { positions based on the zoom level, filters, } \\
\text { attribute value, and adjacent axis could } \\
\text { assist with decreasing visual clutter and } \\
\text { increasing the precision of the filter. }\end{array}$ \\
\hline [103] & Facet graphs & $\begin{array}{l}\text { Enables individuals to } \\
\text { access data contained } \\
\text { in the Semantic Web } \\
\text { in accordance with } \\
\text { their semantics }\end{array}$ & $\begin{array}{l}\text { Uses football field } \\
\text { examples }\end{array}$ & $\begin{array}{l}\text { Facets are } \\
\text { represented as a } \\
\text { node graph } \\
\text { visualization and } \\
\text { can be added and } \\
\text { removed } \\
\text { interactively by } \\
\text { the users }\end{array}$ & None & $\begin{array}{l}\text { Tools are described as something that, } \\
\text { according to their semantic descriptions, } \\
\text { enables people to access data stored in the } \\
\text { web. A: challenges include massive data } \\
\text { volumes, massive semantic relationships } \\
\text { within the data, and highly complex search } \\
\text { queries. D: appropriate zooming } \\
\text { functionality must be integrated with } \\
\text { conjunction with a focus and context } \\
\text { method to encourage users to maintain an } \\
\text { overview even when using huge facet sizes } \\
\text { in a single graph. }\end{array}$ \\
\hline [104] & Refinery & $\begin{array}{c}\text { Interactive } \\
\text { visualization system } \\
\text { described by } \\
\text { associative browsing } \\
\text { attributes taken from } \\
\text { ES }\end{array}$ & $\begin{array}{l}\text { Visualizes query } \\
\text { nodes that are } \\
\text { within the results } \\
\text { subgraph, gives } \\
\text { explanatory context, } \\
\text { and facilitates } \\
\text { serendipitous } \\
\text { discovery }\end{array}$ & $\begin{array}{l}\text { Presents the } \\
\text { outcomes of } \\
\text { research } \\
\text { conducted by } 12 \\
\text { scholarly } \\
\text { scientists using } \\
\text { the conference } \\
\text { publishing data } \\
\text { browser system }\end{array}$ & $\begin{array}{c}\text { Ranked by } \\
\text { overall relevance }\end{array}$ & $\begin{array}{l}\text { Examines associative browsing as a } \\
\text { strategy for bottom-up exploration of large, } \\
\text { heterogeneous networks. A: these } \\
\text { guidelines motivate the refinery's query } \\
\text { model, which allows users to simply and } \\
\text { expressively construct queries using } \\
\text { heterogeneous sets of nodes. D: nothing is } \\
\text { collection-specific in strategy; in almost } \\
\text { every collection, you need to use two } \\
\text { categories: time and phrases. }\end{array}$ \\
\hline [105] & $\begin{array}{l}\text { Multiple view } \\
\text { faceted } \\
\text { interface micro } \\
\text { visualizations }\end{array}$ & $\begin{array}{l}\text { A novel version of the } \\
\text { RD instrument was } \\
\text { launched to explore } \\
\text { and analyze } \\
\text { recommended } \\
\text { outcomes }\end{array}$ & $\begin{array}{l}\text { Provided visual } \\
\text { representation for } \\
\text { FS using } \\
\text { streamlined, data } \\
\text { type-specific micro } \\
\text { visualization } \\
\text { representations }\end{array}$ & $\begin{array}{l}\text { Micro } \\
\text { visualization } \\
\text { filters were used; } \\
\text { for comparison, } \\
\text { the equivalent } \\
\text { text-based faced } \\
\text { descriptors were } \\
\text { displayed }\end{array}$ & $\begin{array}{l}\text { Provides } \\
\text { transparency on } \\
\text { the impact of } \\
\text { specific topical } \\
\text { interests on rec- } \\
\text { ommendations' } \\
\text { ranking }\end{array}$ & $\begin{array}{l}\text { Consists of one primary visualization for } \\
\text { information exploration and several } \\
\text { miniaturized visualizations displaying the } \\
\text { filters. A: the goal is to decrease user load } \\
\text { and to optimize screen area usage. D: in the } \\
\text { long run, micro visualizations need to be } \\
\text { interactive, as well as ways to realize an } \\
\text { optimized version of the RD for tiny screen } \\
\text { mobile devices. }\end{array}$ \\
\hline [106] & $\begin{array}{l}\text { Graphs } \\
\text { selected }\end{array}$ & $\begin{array}{l}\text { Manual chart } \\
\text { construction with } \\
\text { interactive navigation } \\
\text { of a variety of } \\
\text { automatically } \\
\text { generated } \\
\text { visualizations }\end{array}$ & $\begin{array}{l}\text { IMDB and Rotten } \\
\text { Tomatoes }\end{array}$ & $\begin{array}{l}\text { Mixed-initiative } \\
\text { scheme } \\
\text { supporting the FS } \\
\text { of suggested } \\
\text { graphs selected } \\
\text { on the basis of } \\
\text { statistical and } \\
\text { perceptual } \\
\text { measures }\end{array}$ & $\begin{array}{l}\text { Various rankings } \\
\text { of relevance } \\
\text { based on } \\
\text { statistical } \\
\text { measures }\end{array}$ & $\begin{array}{l}\text { Visualization tools require manual view } \\
\text { specification: analysts must choose data } \\
\text { variables and then choose which } \\
\text { transformations and visual encoding to use. } \\
\text { A: explore models of probabilistic } \\
\text { recommendations that can learn better } \\
\text { ranking features over time D: supplement } \\
\text { manual chart building with interactive } \\
\text { navigation of a gallery of visualizations } \\
\text { generated automatically. }\end{array}$ \\
\hline [107] & Receptor & $\begin{array}{l}\text { Graph search } \\
\text { functionalities by } \\
\text { automatically } \\
\text { translating the text } \\
\text { query into nodes }\end{array}$ & $\begin{array}{l}\text { A system to assist } \\
\text { sensitivity } \\
\text { reviewers by } \\
\text { searching large } \\
\text { collections to find } \\
\text { latent relations }\end{array}$ & $\begin{array}{l}\text { Faceted search } \\
\text { with various } \\
\text { search filters such } \\
\text { as document } \\
\text { creation date, } \\
\text { authors, and } \\
\text { origins. }\end{array}$ & None & $\begin{array}{l}\text { Is a new solution that aims to provide } \\
\text { sensitivity reviewers with the ability to } \\
\text { explore a collection of documents to } \\
\text { discover latent relations between entities } \\
\text { and events that can be a reliable indicator } \\
\text { of sensitive information. }\end{array}$ \\
\hline [108] & $\begin{array}{l}\text { Map-based } \\
\text { faceted } \\
\text { exploration } \\
\text { model }\end{array}$ & $\begin{array}{l}\text { Map-based faceted } \\
\text { exploration model }\end{array}$ & $\begin{array}{l}\text { Shared data for user } \\
\text { collaboration }\end{array}$ & $\begin{array}{c}\text { Faceted } \\
\text { exploration } \\
\text { model }\end{array}$ & $\begin{array}{l}\text { Ranked-list } \\
\text { visualization }\end{array}$ & $\begin{array}{l}\text { Model is based on interactive widgets, } \\
\text { which support information exploration at } \\
\text { two granularity levels, i.e., by projecting a } \\
\text { map on specific data categories and/or } \\
\text { according to specific attributes of items. D: } \\
\text { Depending on their roles, users might need } \\
\text { to access different, long-lasting custom } \\
\text { views of shared information space in } \\
\text { some scenarios. }\end{array}$ \\
\hline
\end{tabular}


Table 3. Cont.

\begin{tabular}{|c|c|c|c|c|c|c|}
\hline Ref & Model & Framework & Data Collection & Faceted Used & Ranking & $\begin{array}{c}\text { Improvement, A: Advantages, } \\
\text { D: Drawbacks }\end{array}$ \\
\hline [109] & FS & $\begin{array}{l}\text { Retrieves data from a } \\
\text { scholarly knowledge } \\
\text { graph, which can be } \\
\text { compared and filtered } \\
\text { to satisfy user } \\
\text { information needs } \\
\text { better }\end{array}$ & Google Scholar & $\begin{array}{l}\text { Dynamic facets, } \\
\text { which means } \\
\text { facets are not } \\
\text { fixed and will } \\
\text { change according } \\
\text { to the content of a } \\
\text { comparison }\end{array}$ & None & $\begin{array}{l}\text { Implemented an FS system over a scholarly } \\
\text { knowledge graph. The system provides the } \\
\text { opportunity to save these configurations } \\
\text { and the subset of retrieved data as a new } \\
\text { comparison to the database, with a } \\
\text { permanent URL that can be shared with } \\
\text { other researchers and users. Federated } \\
\text { knowledge graphs to improve dynamic FS } \\
\text { further. For instance, it is intended to use } \\
\text { GeoNames to enable spatial filtering on } \\
\text { scholarly knowledge. }\end{array}$ \\
\hline
\end{tabular}

\subsection{Evaluation Metrics}

The fourth category included thirty-six articles focused on various techniques used to evaluate the different FS implementations. Generally, two metrics have been used to assess and evaluate FS, namely: objective metrics and subjective metrics.

RQ3. What are the existing gaps for research prospects in the faceted search approach of web search services?

\subsubsection{Objective Metrics}

These were evaluated through the objective metrics, which can be classified into two types: relevance metrics and cost-based metrics:

Relevance metrics: In FS, the matching between data items and facet terms in many cases is predetermined. Only a tiny number of FS systems support the automatic classification of search results based on facet terms [22,110]. Therefore, the relevant metrics of FS results are always high. However, the community of information retrieval has introduced several metrics to describe FS's binary and graded relevance. For binary relevance, the E-measure with their macro and micro forms, the F-measure, precision, and recall are considered primary metrics. For instance, the authors of [111,112] employed micro-F1, macro-precision, and macro-recall to evaluate the results of the deep classifier in FS. Moreover, Gomadam used precision and recall to measure the search process of FS. Meanwhile, the rank-biased precision [113], normalized discounted cumulative gain [114], mean reciprocal rank [115], binary preference [116], and mean average precision [117] are considered as the main graded relevance metrics [118-120]. Alternatively, [76,121-123] exploited normalized discounted cumulative gain to rank the output of their facet discovery algorithms.

Cost-based metrics: These are used to investigate the time consumption and memory usage of the FS system. In this regard, one paper [124] calculated the completion time of retrieval tasks to describe the efficiency of FS in mobile devices. Furthermore, [125] applied two cost-based metrics: the time spent on calculating the number of attribute-value pairs of facet terms and the memory usage in the index storing process [126-128].

\subsubsection{Subjective Metrics}

Contrary to objective metrics, the subjective metrics assess and evaluate the simplicity and flexibility of FS [129-135]. Two main methods are usually used here, namely intrinsic and extrinsic evaluations:

Intrinsic evaluations: Standard query facets are built by human annotators and used as the ground truth to compare with facets produced by separate schemes [136,137]. Usually, facet annotation is performed by first pooling facets produced by the separate schemes $[138,139]$. Annotators are then asked to group or regroup terms into preferred query facets in the pool and to offer scores for each of the query facets [140,141], as can be seen in Figure 7.

The general intrinsic evaluation steps of the FS system are summarized as follows: (1) human annotators build the facets of the query; (2) the ground truth is compared with 
multisystem facets; (3) in order to group or regroup conditions into preferred query facets in the pool, annotators are asked to pool facets produced by different technologies.

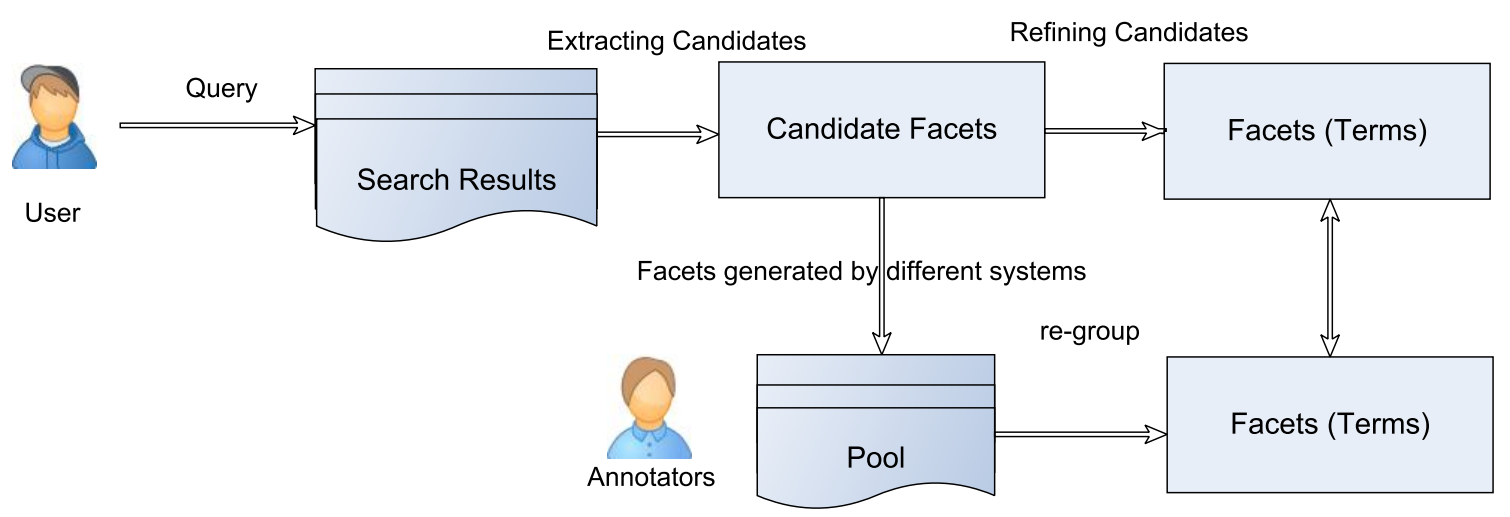

Figure 7. General intrinsic evaluation of a faceted search system.

It is worth mentioning that the intrinsic evaluation is not based on any particular search task. It thus may not reflect the actual utility of the generated facets in assisting the search. Therefore, the extrinsic evaluation has been proposed and applied by many related works:

Extrinsic evaluation: This is a system based on an interactive search task that incorporates FS [142,143]. The general extrinsic evaluation steps for a faceted search system are as follows: (1) evaluate a system based on an interactive search task that incorporates FS; (2) the gain can be measured by the improvement of the reranked results; (3) the cost can be measured by the time spent by the users giving facet feedback; (4) based on the user model, we can estimate the time cost for the user, as can be seen in Figure 8.

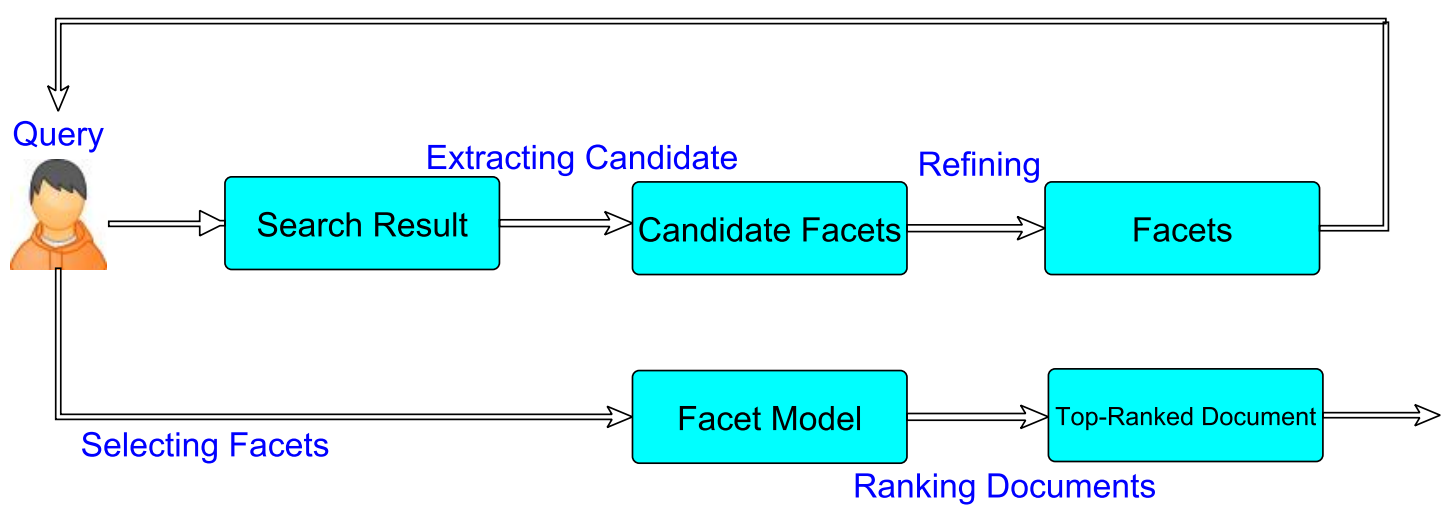

Figure 8. General extrinsic evaluation of a faceted search system.

\subsection{Faceted Technologies}

The five categories included forty-four articles focused on the fundamental idea in FS being to solicit and capture keywords supplied by a user from which to prune out branches of the hierarchy irrelevant to the user's information need. This style of search can be applied to both faceted (e.g., a unidimensional version of Epicurious) and unfaceted sites (e.g., ODP). FS over a faceted site typically involves matching the terms in the query to the available values for the facets remaining unfilled to simplify the hierarchy at any point. FS techniques integrate navigational (e.g., Yahoo!) and direct search (e.g., Google) to help users determine which portions of a classification contain the information desired. In other words, they combine browsing and search, leading to a mixed-initiative mode of interaction. FS is broad and refers to a family of related search techniques for information 
hierarchies as variations on this idea. In this section, we discuss the idea and showcase a few specific examples. Search results' ranking in FS is similar to that in the traditional IR domain. It has been extensively studied for years [144,145].

\subsubsection{Dynamic Faceted Search}

This extends traditional FS to support more prosperous information discovery tasks over more complex data models. The ability to view flexible and dynamic aggregations over faceted data as typically found in business intelligence applications over structured data would allow users to make more informed drill-down and roll-up choices, which will support them in making better decisions [146]. Typical FS applications operate over a set of (predetermined) indexed facets, i.e., the facets and attributes associated with each document must be known at indexing time.

The articles [146,147] extended traditional FS to support more prosperous information discovery tasks over more complex data models. The ability to view flexible and dynamic aggregations over faceted data as typically found in business intelligence applications over structured data would allow users to make more informed drill-down and roll-up choices, which will support them in making better decisions.

The articles in $[148,149]$ extended traditional FS over more advanced data systems to promote a vast amount of data discovery tasks. The proposed solution would work if the underlying data source can evaluate a ranked list of tuples. References [150,151] described a structure for an e-commerce dynamic ordering system. The structure discussed particular elements of e-commerce, such as the possibility of numerous hits, the classification of factors by their respective characteristics, and the wealth of numerical elements, unlike current alternatives. Others [152,153] described the choice of different categories within the Semantic Web setting with priority given to implementing the decision-making assistance scheme, the ontological visual facet navigation system.

\subsubsection{Hierarchy Construction}

In query interfaces, hierarchical categories were used early on. The search results, which represent hierarchical tags, can assist consumers in defining or further refining (or expanding) applications. SEs, such as the Yahoo search engine and OpenDirectory, are relevant, but each show a human hierarchical classification; consumers can browse through the hierarchical class folder taking a hyperlink of the topic. Additional schemes assist consumers in defining suitable subsets from massive outcomes by arranging outcomes into hierarchical categories [154].

In the field of FS hierarchy building, there have been several works. The conventional paradigm for keyword Google data pages (a catalog of documents ordered by relevance) makes the findings slightly connected with the general data area. Search settings, therefore, do not entirely misuse the value of the intrinsic attributes of the hierarchy. Adverse schemes also typically do not show the entire magnitude of the accessible hierarchical metadata, which also leaves identifying the models or connections between facets tough $[155,156]$.

The authors in $[157,158]$ used input to divide tasks and allow designers to discover a familiar technology through new relationships. In an attempt to allow designers to manage complicated computer environments flexibly, they introduced a strategy that characterizes code pieces and some other aspects.

\subsubsection{Facet Interface}

This combines data-oriented text assessment with a new GUI layout to enhance device assistance for browsing and choice in company data collection. A facet-based software intended to operate at an Internet printer offers a wealth of customer knowledge that combines search and navigation approaches for a location.

Some related studies have proposed analytical search tools that present a fresh collection of scheme assessment methods. However, there is still a lack of metrics reflecting the required outcomes. ES applications invariably require the effective involvement of 
customers, which means that the variability of the customers in the experimental layout must be counterbalanced [159]. Many works, particularly the work guided by $[160,161]$, have focused on these aspects.

Facet ranking: If too many facets or facet terms exist, or the user interface has limited space to show most of them, only certain facets or terms are required. This needs a classification of the facets and conditions to select the most significant facets. The literature recognized two main types of facet ratings autonomous facets and the corresponding facets. The leading e-commerce sites (Amazon, eBay) use the FS of structured data, which typically shows all aspects of the present search result collection that are relevant. When too many attributes exist for one facet, the most common is displayed to the user, and the remainder is hidden with a "more" button. The first FS introductory version describes facets of an app with a user interface perspective. Standings in combination with a faced interface could be applied [162,163]. The autonomous fact-based evaluation techniques are primarily dependent on the identification ability of facet-based frequencies [164-167].

The first group introduced a faceted query strategy and classification of web APIs, which considers API characteristics or facets identified in their HTML illustrations. Furthermore, the query engine opportunities that permit a classification depending on weighted query conditions and facet conditions were explored [168-171].

The second group presented idea analysis and increased the classification by defining the primary subjects of articles, combining reinforcement learning with a new customer interaction layout to involve people in query management actively. This document, ranking SVM, was used to build a model ranking for the precise bug reports, learning to rank technology [172-175].

The third group suggested model description and FS application search algorithms move to a web of objects knowledge. It provided characteristics for rank facets depending on the usefulness of the test outcome records for partitioning. The scheme's architecture also has its primary elements and its implementation as a portion of the query environment for the images [176-180].

Lastly, the final group described metaservices without prior indexing of the data stacks surrounding them. In addition, it suggested a set of fusion-based techniques for the sustainability of results to enhance efficiency, both that which is relevant and diverse. Experimental findings indicated that specific fusion methods that use the above techniques work better than cutting-edge fusion processes for diversifying outcomes [181-184];

Faceted navigation-based XML search: For many applications, XML is now the conventional data format, and accurate recovery techniques are desired. Generally, there are approximately two types of recall methods, notably path-based methods and search for keywords, and they do not work if users do not need any tangible data. This is to increase XML data recovery effectiveness [185].

FS articles focused on types of applications provided on XML data to enable consumers to discover the information needed from XML data by specifying variable content sets for the present query findings. The main application was also demonstrated, which is an integrated FS in nephrology based on information extraction results. The suitable conditions to summarize the present outcomes with the components of the verbal faces were obtained [186,187].

\section{Discussion}

Relevant studies on state-of-the-art faceted search-based filtering were presented in this review. The primarily aims was to provide a new vision for faceted search and highlight research trends in this area. The survey revealed three aspects of the literature content: challenges in successfully utilizing these applications, recommendations to alleviate these difficulties, and the proposed general framework for the search and browse procedure. Topics related to faceted search based on information filtering are described in Figure 9. 
RQ4. What are the existing motivations for usage, concerns, challenges, and recommendations to enhance the use of the faceted approach of web search service providers?

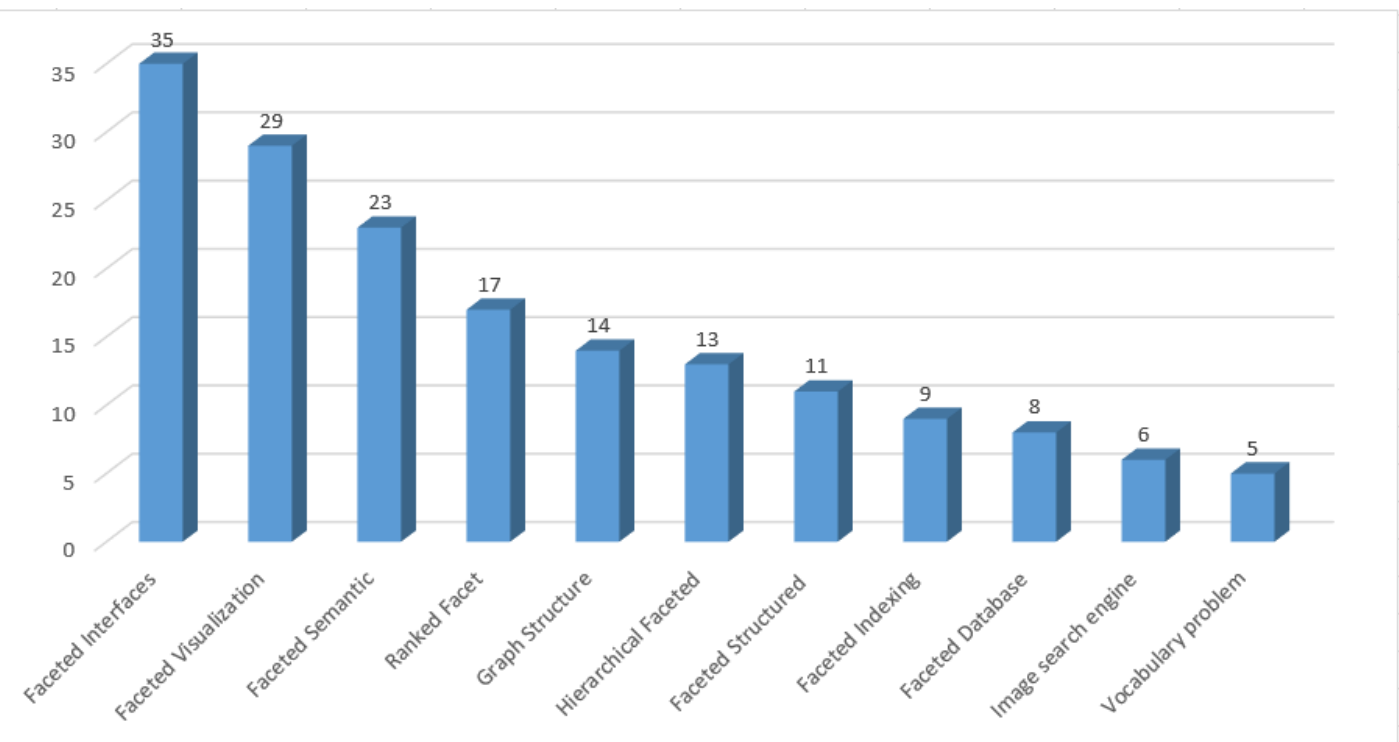

Figure 9. Topics related to faceted search based on information filtering.

\subsection{Challenges}

Although FS based on information filtering offers numerous benefits, these applications have limitations in SEs. The surveyed works indicated that researchers are concerned about challenges associated with FS and their use based on information filtering. The main challenges in adopting FS are classified according to their nature, presented in this section, and citations for further discussion are given. Although smart FS offers numerous benefits, the evaluation metrics demonstrate that these technologies are limited by information overload [9]. The surveyed works indicated that researchers are concerned about the challenges associated with information filtering and its use. The main challenges in adopting FS are listed below, along with citations for further discussion. The challenges are classified according to their nature (see Figure 10).

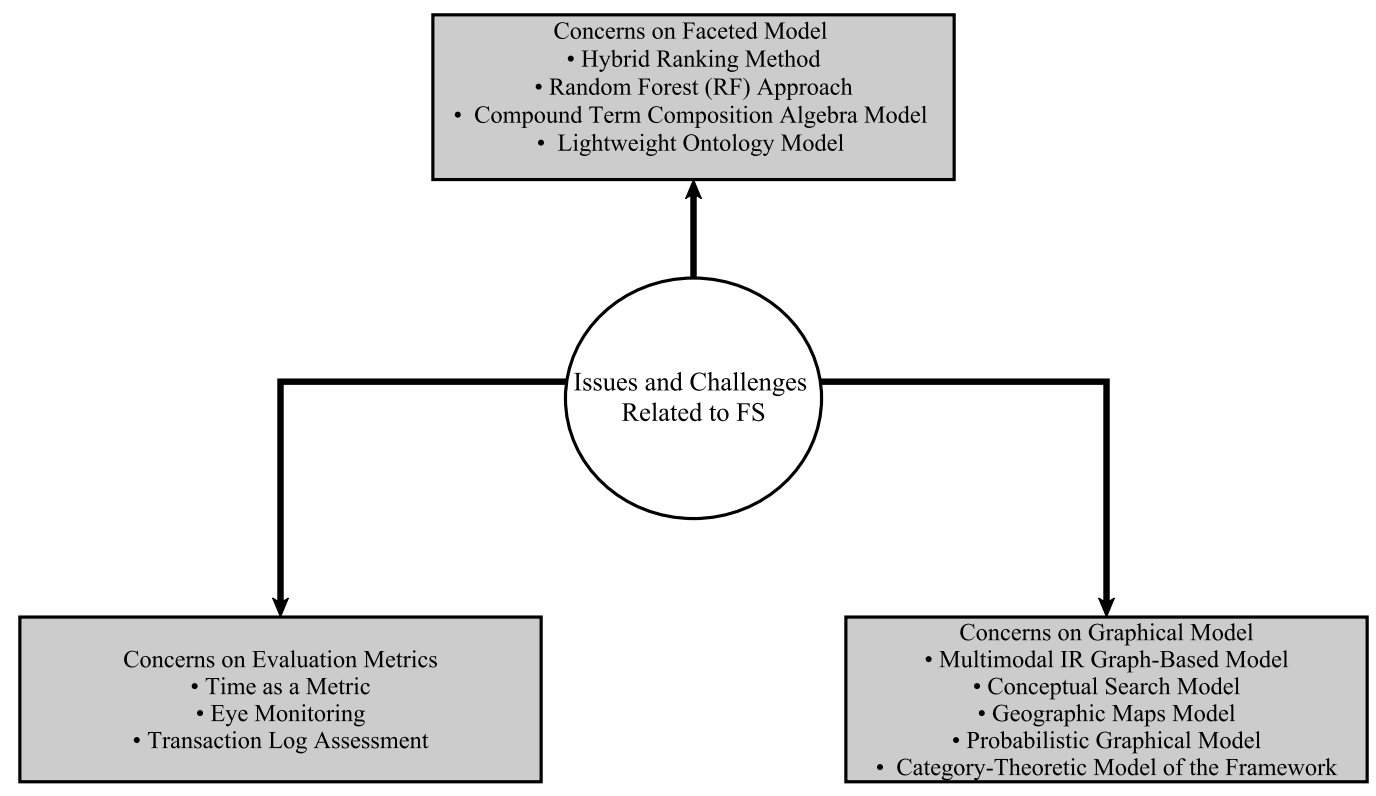

Figure 10. Categories of challenges for faceted search based on information filtering. 


\subsubsection{Faceted Model}

Several researchers have focused on faceted models. Four typical set theory-based models are presented below.

Several researchers have focused on faceted models. Four typical set theory-based models are presented below: (1) the hybrid ranking graph-based approach, which describes facets as an imminent characteristic of object information, can also illustrate the information itself [52]; (2) Random Forest (RF) uncovers non-influential search-flexible variables; the RF model suggested that the minimal effect of cumulative action history on the facet addition verifies the findings of this work, which are similar to the fundamental context of long short-term memory [53]; (3) the theoretical model of compound term composition algebra (CTCA), which flexibly and effectively identifies important terms compared with the faceted taxonomy; being appropriate and effortlessly, it defines valid and invalid compound terms [188,189]; (4) the lightweight ontology model of a website and a context similarity approach to reorder facet queries; the lightweight ontology presumes that information may be duplicated in a multilist website; context similarity can enhance facets using finegrained similarities, although unique facets of weighting can be obtained from different websites [61].

\subsubsection{Graphical Models}

Four typical graphics-based models are discussed in this section. The multimodal IR graph-based model combines distinct modes through face search formulation and models distinct information collection types with unique methods and connection types. (1) A conceptual search model is build that is suitable to describe various user actions in searching and exploring semantic data. The search model analyses facet graphs in terms of general data search demands, which are constructed in conjunction with semantically specific queries of graph visualization based on FS [96,190]. (2) Based on the Bayesian suggestion algorithm, a large amount of data that are widely used on the enterprise search platform Solr is visualized. The Bayesian suggestion algorithm and the probabilistic graphical model capture facet dependencies and determine valuable facets to be presented to users [191]. (3) Text in each visualization, such as clouds, are used to determine the frequency of words or phrases; word trees obtain the context surrounding a word or phrase, and phrase nets provide relationships between words or phrases that are unique [192-195]. (4) These can order facets by user's values and objects using best, worst, preferTo (relative preferences), aroundTo (over a specific value), and other actions that can order them lexicographically or based on their values or count values. The use of geographic maps to display focus items during the interaction and as inputs implies that the focus is restricted, and the preferences are defined [97].

\subsubsection{Evaluation Metrics}

Emotional reactions are typically gathered using post search questionnaires to evaluate the respondent's understanding of the scheme [63]. (1) Time as a metric is controversial because time is unsuitable for measuring exploratory assignments. The rapid completion of an exploratory task may suggest the absence of support in a search system for investigating and exploring [18]. (2) Eye monitoring stimulated recall and interviews to explore significant elements of gaze conducted in the face catalog interface. The top 10 gaze transitions derived from eye-tracking information indicate what searchers are looking in in the faceted interface and suggest the relevant portion or element of the interface [32]. (3) Evaluating ES, assessment research aimed to assess hypotheses about customer needs and system specifications from prospective customers' perspectives and adopt either transaction log assessment or user testing, as well as to understand the search conduct of customers with the faceted interface [136]. 


\subsection{Future Research Directions and Recommendations}

Although FS has been extensively explored, several issues still need to be addressed. We gathered and described feasible and potential future investigations on faceted search (see Figure 11).

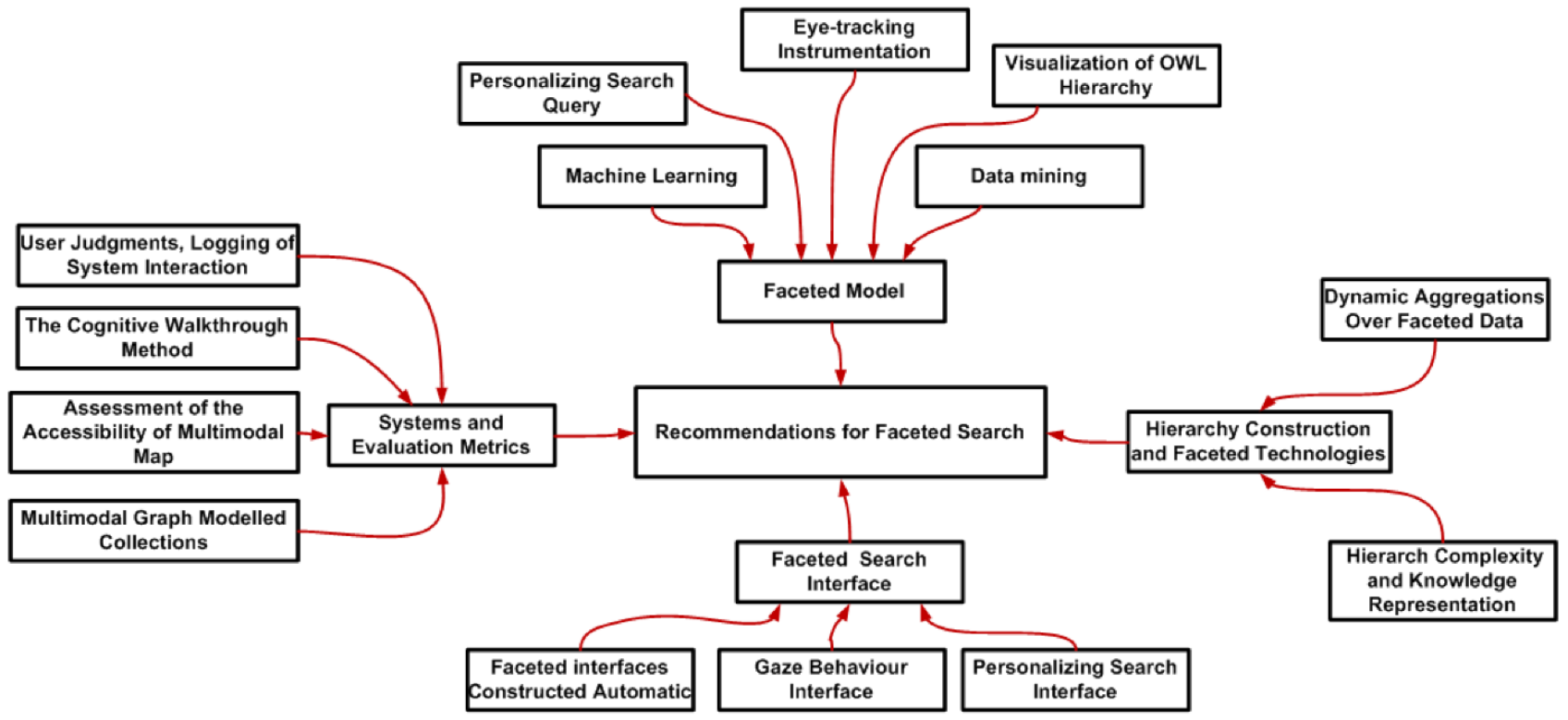

Figure 11. Categories of recommendations on faceted search.

\subsubsection{Faceted Search User Interface}

Users can confidently expand certain facets in the hierarchy of faceted interfaces, and web results can then be sectioned to enable switching to other hierarchies whilst browsing. These multifaceted interfaces allow the exposure of web content and help users rapidly find items of interest. The majority of faceted interfaces in current systems are manually constructed. Building strategies for the automated development of faceted interfaces is an important task that allows extensive faceted interfaces. Facets help improve the user experience for structured web searches. The following challenges must be addressed to utilize SE facets effectively: (1) given the restricted screen display property and wide range of possible facets, selecting the top-k vital facets is necessary, where $\mathrm{k}$ is generally a small quantity; (2) many structured data sources are available on engines, such as Amazon or Google. If the information is summarized as denormalized entity-type tables, thousands of such tables must be remembered [125].

Future investigations can focus on assessing additional interface factors and their impact on gaze behavior regarding the number of facets, matching the degree of facets with the topic/task, searcher domain knowledge, and search experience, the stage of the search, and high-level work task situations. Guidelines for possible work from a theoretical perspective have been proposed to examine the application of faceted issues with additional features suggested by practice, especially in negation sorting. Comprehensive face-related query features are also assessed in the ontology.

\subsubsection{Faceted Model}

The use of databases, data mining, machine learning, and other methods was suggested in the FS of [196]. These research areas are intended to focus on the contents and schemes of a database further by producing a reduced version that can describe the data at various granularity levels. Multiple methods, including random hikes, hierarchical clustering, and probabilistic synthesizing, are introduced to synthesize lists and opinions. Search databases are independent of queries; therefore, such methods are insufficient in 
handling all the searches, although the findings of a particular question can be summarized during each phase.

In summary, this study investigated customer relationships with facets to comprehend real-time facet use during searching apart from current searches in creating algorithms for FS and empirical research in facet evaluation. Data mining and machine learning methods were used to connect facets, find vibrant variables, and improve search results [53].

Other future studies can also explore detection when queries have minimal ambiguity in intent, but seek content to cover various aspects and learn semantic query annotations suitable for the target purpose of each query. Such studies focus on personalized search based on models representing individual needs and intentions of users that can model the topical and even cognitive aspects of user intentions.

\subsubsection{Faceted Search Systems and Evaluation Metrics}

Several methods have been used to evaluate information retrieval systems from the point of view of their users. Each evaluation method concentrates on specific goals (e.g., evaluation of usability, usefulness, or retrieval performance of a system) and is subjected to different constraints. User involvement can take the form of relevance judgments, logging of system interaction, and observations of information-seeking behavior with the system.

The study aimed to evaluate the view of the assumptions of potential users. The method devised for this evaluation, denoted participative conceptual walkthrough, combines aspects of the cognitive walkthrough method from HCI with ideas from conceptual analysis and other established approaches. This method aims to evaluate the interactive information retrieval of the development process in the early stages and incorporate domain knowledge into the development of conceptual frameworks.

RQ5. What are the points of interest, such as the architecture, applications, issues, research questions, motivations, recommendation criteria, and open challenges, in using faceted search?

\subsubsection{Faceted Technologies and Hierarchy Construction}

Guided navigation tools can be significantly enhanced beyond essential search facets by understanding information further. The capacity to display versatile and vibrant aggregations over faceted information as typically seen in organized information in business intelligence applications can enable additional educated push-back and roll-up customer choices that can lead to solid decisions. Another problem is creating a fundamental data model in FS because of its minimal real-life information, which links records to pairs of principles across multiple facet hierarchies. For instance, papers describing products can demonstrate connected facet characteristics, which are dependent or unrelated (see Figure 12).

Hierarchical FS metadata, a highly understandable data model for SE interfaces, is intermediate in complexity between hierarchy and full knowledge representation. Although websites, especially e-commerce sites, have typically used category information for navigation, applications are commonly inconsistent, incomplete, or problematic in many cases. A device that uses metadata to access the digital library is an original efficiency survey, which allows the visual detection of implicit correlations between facets. Faceted systems typically hide the full extent of the available hierarchical metadata, making it difficult to identify patterns or linkages between facets. Thus, faceted environments are an exciting possibility for further investigations and refinement.

The first feature produces all the appropriate composite conditions consisting of one or more facet variables to ensure that the composite form chosen by the customer can be determined. The second function of facet ranking and facet representation is suitable for the inquiry, and the third user function is fed back from the designated SE facet terms. (a) Precalculation of paper facets and facet conditions (b) can take facets out of the study results. Two distinct and dynamic methods are available. The scheme changes the number of information pieces corresponding to facet conditions on the user interface and recounts 
facet conditions around the exact moment for to follow navigation activities. Iterations proceed until the outcomes are achieved. Previous sections discussed how to build a unified template for heterogeneous XML data.

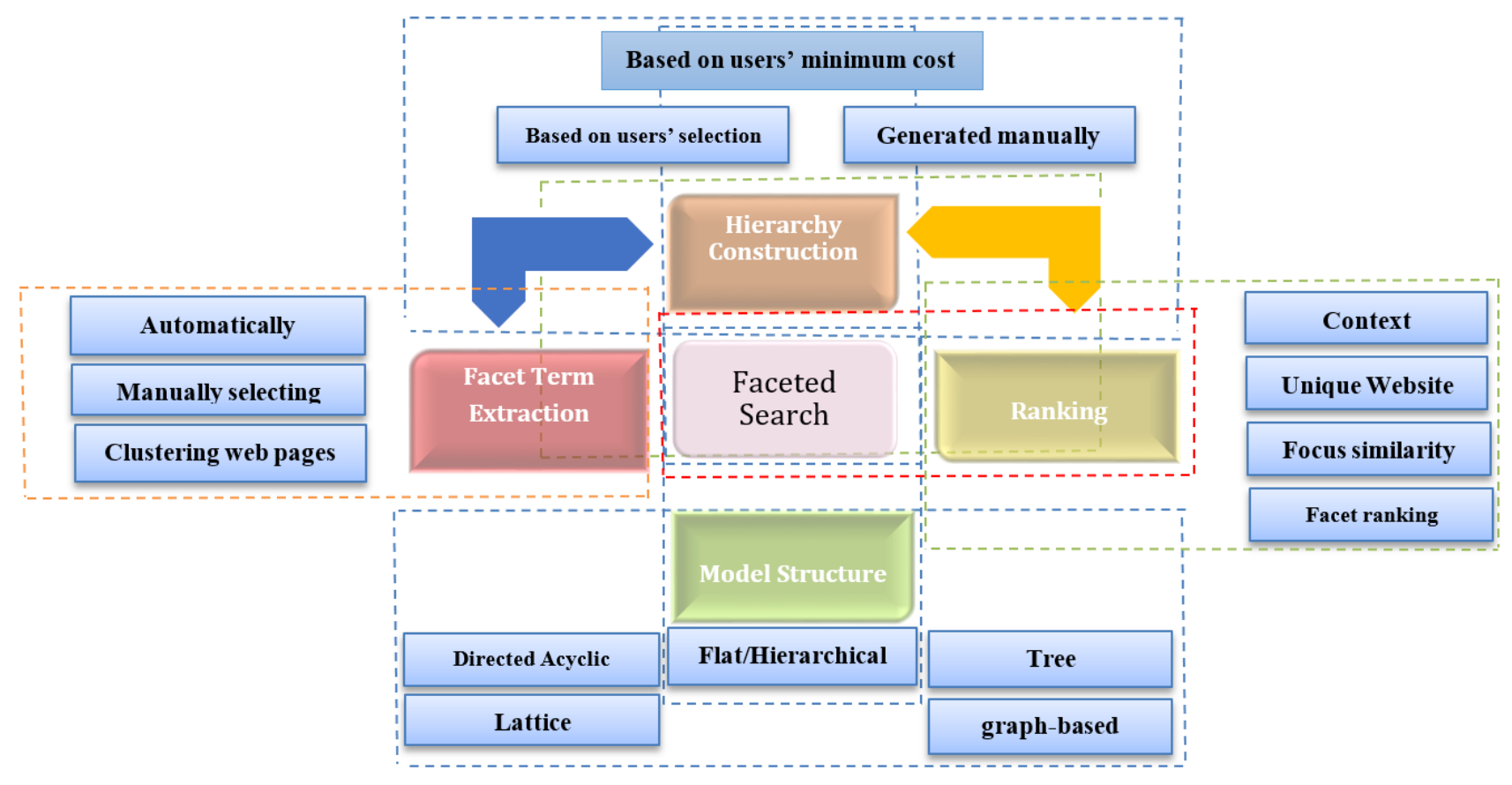

Figure 12. General framework. for a faceted search system.

Personalized search schemes and ES applications have attracted considerable research attention. The strength of synthetic intelligence methods was investigated separately to provide customized query outcomes following distinct customer concerns, environments, and duties. However, ES capitalizes on the strength of human intelligence and offers consumers strong web engines. They can reinforce each other because of the consistency of these methods. This study argued that customized survey schemes can improve this by enabling customers to communicate with the scheme and learn about the issue to achieve their end objective.

\section{Conclusions}

In this article, the descriptive faceted search model was reviewed and analyzed. Moreover, the progression of its techniques, including removing facet words, hierarchy, and facet classification, was described. Furthermore, we discussed the evaluation metrics of faceted search by highlighting the main characteristics of existing faceted search systems. Therefore, the fundamental features of this evolving area were identified, and the motivations and difficulties for using FS applications were demonstrated carefully. Furthermore, this paper highlighted many potential studies that can be undertaken, including automated faceted taxonomic design and visualization, significance assessment for FS outcomes, faceted interfaces, hierarchical structure, and graphic design. Our recommendations provided solutions to many challenges related to the use of faceted search. These challenges are linked to facet term extraction, hierarchy construction, compound term generation, and facet ranking. Finally, this review summarized the ideas of the related literature, thereby presenting a valuable reference for researchers.

Author Contributions: Conceptualization, M.N.M. and A.R.A.; methodology, M.N.M. and A.R.A.; validation, M.N.M. and H.N. and A.R.A.; formal analysis, H.N. and M.A.S.; investigation, M.N.M. and Q.S.Q.; resources, M.N.M., Q.S.Q. and A.R.A.; data curation, M.N.M., H.N. and A.R.A.; writing-original draft preparation, M.N.M. and A.R.A.; writing—review and editing, M.N.M., H.N., 
and A.R.A; visualization, M.N.M. and H.N.; supervision, M.N.M. and Q.S.Q.; project administration, A.R.A.; funding acquisition, A.R.A. All authors have read and agreed to the published version of the manuscript.

Funding: Universiti Tenaga Nasional (UNITEN), Innovation and Research Management Center (iRMC): J510050783 (2018).

Institutional Review Board Statement: Not applicable.

Informed Consent Statement: Not applicable.

Data Availability Statement: Not applicable.

Acknowledgments: This research was sponsored and supported under the Universiti Tenaga Nasional (UNITEN) internal grant no J510050783 (2018). Many thanks to the Innovation and Research Management Center (iRMC), UNITEN who provided their assistance and expertise during the research.

Conflicts of Interest: The authors declare no conflict of interest.

\section{References}

1. Nargesian, F.; Pu, K.Q.; Zhu, E.; Bashardoost, B.G.; Miller, R.J. Organizing Data Lakes for Navigation. In Proceedings of the 2020 ACM SIGMOD International Conference on Management of Data, Portland, OR, USA, 14-19 June 2020; pp. $1939-1950$.

2. Jo, Y.; Wi, J.; Kim, M.; Lee, J.Y. Flexible Fashion Product Retrieval Using Multimodality-Based Deep Learning. Appl. Sci. 2020, 10, 1569. [CrossRef]

3. Xu, J.; Croft, W.B. Quary Expansion Using Local and Global Document Analysis. SIGIR Forum 2017, 51, 168-175. [CrossRef]

4. Sacco, G.M. SAES: An Introduction to Self-Adapting Exploratory Structures. Future Internet 2019, 11, 54. [CrossRef]

5. Langville, A.N.; Meyer, C.D. Google's PageRank and Beyond: The Science of Search Engine Rankings; Princeton University Press: Princeton, NJ, USA, 2011.

6. White, R.W.; Roth, R.A. Exploratory Search: Beyond the Query-Response Paradigm; Synthesis Lectures on Information Concepts, Retrieval \& Services; Morgan and Claypool Publishers: San Rafael, CA, USA, 2009; Volume 3.

7. Marchionini, G. Exploratory search: From finding to understanding. Commun. ACM 2006, 49, 41-46. [CrossRef]

8. Tunkelang, D. Faceted Search; Synthesis Lectures on Information Concepts, Retrieval, and Services; Morgan \& Claypool Publishers: San Rafael, CA, USA, 2009; Volume 1, pp. 1-80.

9. Mahdi, M.N.; Ahmad, A.R.; Ismail, R.; Natiq, H.; Mohammed, M.A. Solution for Information Overload Using Faceted Search-A Review. IEEE Access 2020, 8, 119554-119585. [CrossRef]

10. Wang, M.; Li, D. An empirical investigation of the continuance intention using the bullet curtain: Synchronicity vs information overload. Chin. Manag. Stud. 2019, 13, 235-254. [CrossRef]

11. Büttcher, S.; Clarke, C.L.; Cormack, G.V. Information Retrieval: Implementing and Evaluating Search Engines; Mit Press: Cambridge, MA, USA, 2016.

12. Singer, G.; Danilov, D.; Norbisrath, U. Complex search: Aggregation, discovery, and synthesis. Proc. Est. Acad. Sci. 2012, 61, 89. [CrossRef]

13. Nightingale, A. A guide to systematic literature reviews. Surgery (Oxford) 2009, 27, 381-384. [CrossRef]

14. Munn, Z.; Peters, M.D.; Stern, C.; Tufanaru, C.; McArthur, A.; Aromataris, E. Systematic review or scoping review? Guidance for authors when choosing between a systematic or scoping review approach. BMC Med. Res. Methodol. 2018, 18, 143. [CrossRef]

15. Okoli, C. A guide to conducting a standalone systematic literature review. Commun. Assoc. Inf. Syst. 2015, 37, 43. [CrossRef]

16. Pollitt, A.S. A common query interface using MenUSE-A MeNU-based user search engine. Int. Online Inf. Meet. 1988, 12, 444-457.

17. Mahdi, M.N.; Ahmad, A.R.; Ismail, R. Improving faceted search results for web-based information exploration. Int. J. Adv. Sci. Eng. Inf. Technol. 2020, 10, 1143-1152. [CrossRef]

18. Capra, R.; Marchionini, G. Faceted Browsing, Dynamic Interfaces, and Exploratory Search: Experiences and Challenges. In Proceedings of the Workshop on Human-Computer Interaction and Information Retrieval, Cambridge, MA, USA, 23 October 2007; pp. 7-9.

19. Yee, K.-P.; Swearingen, K.; Li, K.; Hearst, M. Faceted metadata for image search and browsing. In Proceedings of the SIGCHI Conference on Human Factors in Computing Systems, Lauderdale, FL, USA, 5-10 April 2003; pp. 401-408.

20. Zhang, J.; Marchionini, G. Evaluation and evolution of a browse and search interface: Relation Browser++. In Proceedings of the 2005 National Conference on Digital Government Research, Atlanta, GA, USA, 15-18 May 2005; pp. 179-188.

21. Capra, R.G.; Marchionini, G. The relation browser tool for faceted exploratory search. In Proceedings of the 8th ACM/IEEE-CS Joint Conference on Digital Libraries, Pittsburgh, PA, USA, 16-20 June 2008; p. 420.

22. White, R.W.; Marchionini, G.; Muresan, G. Evaluating exploratory search systems: Introduction to special topic issue of information processing and management. Inf. Process. Manag. 2008, 44, 433-436. [CrossRef]

23. Vickery, B. Faceted classification for the web. Axiomathes 2008, 18, 145-160. [CrossRef] 
24. Zheng, B.; Zhang, W.; Feng, X.F.B. A survey of faceted search. J. web Eng. 2013, 12, 41-64.

25. Athukorala, K.; Głowacka, D.; Jacucci, G.; Oulasvirta, A.; Vreeken, J. Is exploratory search different? A comparison of information search behavior for exploratory and lookup tasks. J. Assoc. Inf. Sci. Technol. 2016, 67, 2635-2651. [CrossRef]

26. Tzitzikas, Y.; Manolis, N.; Papadakos, P. Faceted exploration of RDF/S datasets: A survey. J. Intell. Inf. Syst. 2017, 48, 329-364. [CrossRef]

27. Jacksi, K.; Dimililer, N.; Zeebaree, S.R. A survey of exploratory search systems based on LOD resources. In Proceedings of the 5th International Conference on Computing and Informatics (ICOCI), Istanbul, Turkey, 11-13 August 2015; pp. 501-509.

28. Palagi, E.; Gandon, F.; Giboin, A.; Troncy, R. A Survey of Definitions and Models of Exploratory Search. In Proceedings of the 2017 ACM Workshop on Exploratory Search and Interactive Data Analytics, Limassol, Cyprus, 13 March 2017; pp. 3-8.

29. Hoeber, O. Information Visualization for Interactive Information Retrieval. In Proceedings of the 2018 Conference on Human Information Interaction \& Retrieval, New Brunswick, NJ, USA, 11-15 March 2018; pp. 371-374.

30. Marie, N.; Gandon, F. Survey of linked data based exploration systems. In Proceedings of the IESD 2014-Intelligent Exploitation of Semantic Data, Riva del Garda, Italy, 19-23 October 2014.

31. Jiang, T. Exploratory search: A critical analysis of the theoretical foundations, system features, and research trends. In Library and Information Sciences; Springer: Berlin/Heidelberg, Germany, 2014; pp. 79-103.

32. Zheng, G.; Vaishnavi, V. A multidimensional and visual exploration approach to project prioritization and selection. In Proceedings of the AMCIS 2009 Proceedings, San Francisco, CA, USA, 6-9 August 2009; p. 129.

33. Cleverley, P.H.; Burnett, S.; Muir, L. Exploratory information searching in the enterprise: A study of user satisfaction and task performance. J. Assoc. Inf. Sci. Technol. 2017, 68, 77-96. [CrossRef]

34. Fagan, J.C. Usability studies of faceted browsing: A literature review. Inf. Technol. Libr. 2010, 29, 58-66. [CrossRef]

35. Mahdi, M.N.; Ahmad, A.R.; Ismail, R.; Subhi, M. Review of Techniques in Faceted Search Applications. In Proceedings of the 2020 International Symposium on Networks, Computers and Communications (ISNCC), Montreal, QC, Canada, 20-22 October 2020; pp. 1-5.

36. Kules, B.; Capra, R.; Banta, M.; Sierra, T. What do exploratory searchers look at in a faceted search interface? In Proceedings of the 9th ACM/IEEE-CS Joint Conference on Digital Libraries, Austin, TX, USA, 14-19 June 2009; pp. 313-322.

37. Tzitzikas, Y.; Analyti, A. Faceted taxonomy-based information management. In Proceedings of the 18th International Workshop on Database and Expert Systems Applications (DEXA 2007), Regensburg, Germany, 3-7 September 2007; pp. $207-211$.

38. Perugini, S. Supporting multiple paths to objects in information hierarchies: Faceted classification, faceted search, and symbolic links. Inf. Process. Manag. 2010, 46, 22-43. [CrossRef]

39. Kehrer, J.; Hauser, H. Visualization and visual analysis of multifaceted scientific data: A survey. IEEE Trans. Vis. Comput. Graph. 2013, 19, 495-513. [CrossRef]

40. Polowinski, J. Widgets for faceted browsing. In Symposium on Human Interface; Springer: Berlin/Heidelberg, Germany, 2009; pp. 601-610.

41. Mahdi, M.N.; Ahmad, A.R.; Ismail, R.; Subhi, M.A.; Abdulrazzaq, M.M.; Qassim, Q.S. Information Overload: The Effects of Large Amounts of Information. In Proceedings of the 2020 1st Information Technology to Enhance e-Learning and Other Application (IT-ELA), Baghdad, Iraq, 12-13 July 2020; pp. 154-159.

42. Pass, G.; Chowdhury, A.; Torgeson, C. A picture of search. In Proceedings of the 1st International Conference on Scalable Information Systems, Hong Kong, China, 30 May-1 June 2006; p. 1.

43. Dumais, S. Faceted search. In Encyclopedia of Database Systems; Springer: Boston, MA, USA, 2009; pp. $1103-1109$.

44. Mahdi, M.N.; Ahmad, A.R.; Ismail, R.; Subhi, M.A. Improving Big Data Technologies with Visual Faceted Search. In Proceedings of the 2020 8th International Conference on Information Technology and Multimedia (ICIMU), Beijing, China, 4-6 December 2021; pp. 44-49.

45. Mahdi, M.N.; Ahmad, A.R.; Subhi, M.A.; Ismail, R.; Qassim, Q.S. Visualization in Faceted Search Engine-A Review. In Proceedings of the 2020 IEEE Conference on Big Data and Analytics (ICBDA), Kota Kinabalu, Malaysia, 17-19 November 2020 ; pp. 84-89.

46. Herceg, P.M.; Allison, T.B.; Belvin, R.S.; Tzoukermann, E. Collaborative exploratory search for information filtering and large-scale information triage. J. Assoc. Inf. Sci. Technol. 2018, 69, 395-409. [CrossRef]

47. Sarkas, N.; Bansal, N.; Das, G.; Koudas, N. Measure-driven keyword-query expansion. Proc. Vldb Endow. 2009, 2, 121-132. [CrossRef]

48. Liberman, S.; Lempel, R. Approximately optimal facet value selection. Sci. Comput. Program. 2014, 94, 18-31. [CrossRef]

49. Wille, R. Restructuring lattice theory: An approach based on hierarchies of concepts. In Proceedings of the International Conference on Formal Concept Analysis, Frankfurt, Germany, 25-28 June 2009; pp. 314-339.

50. Giunchiglia, F.; Marchese, M.; Zaihrayeu, I. Encoding classifications into lightweight ontologies. In Journal on Data Semantics VIII; Springer: Berlin/Heidelberg, Germany, 2007; pp. 57-81.

51. Robinson, A.C.; Quinn, S.D. A brute force method for spatially-enhanced multivariate facet analysis. Comput. Environ. Urban Syst. 2018, 69, 28-38. [CrossRef]

52. Sabetghadam, S.; Lupu, M.; Bierig, R.; Rauber, A. A faceted approach to reachability analysis of graph modelled collections. Int. J. Multimed. Inf. Retr. 2018, 7, 157-1718. [CrossRef]

53. Niu, X.; Fan, X.; Zhang, T. Understanding Faceted Search from Data Science and Human Factor Perspectives. Acm Trans. Inf. Syst. (TOIS) 2019, 37, 14. [CrossRef] 
54. Wei, B.; Liu, J.; Ma, J.; Zheng, Q.; Zhang, W.; Feng, B. DFT-extractor: A system to extract domain-specific faceted taxonomies from wikipedia. In Proceedings of the 22nd International Conference on World Wide Web, Rio de Janeiro, Brazil, 13-17 May 2013; pp. 277-280.

55. Katayama, T.; Kawashima, S.; Okamoto, S.; Moriya, Y.; Chiba, H.; Naito, Y.; Fujisawa, T.; Mori, H.; Takagi, T. TogoGenome/TogoStanza: Modularized Semantic web genome database. Database 2019, 2019, bay132. [CrossRef]

56. Chantamunee, S.; Fung, C.C.; Wong, K.W.; Dumkeaw, C. Knowledge discovery from thai research articles by solr-based faceted search. In Proceedings of the International Conference on Computing and Information Technology, Amman, Jordan, 11-12 July 2018; pp. 337-346.

57. de Campos, L.M.; Fernández-Luna, J.M.; Huete, J.F.; Redondo-Expósito, L. Automatic construction of multi-faceted user profiles using text clustering and its application to expert recommendation and filtering problems. Knowl. Based Syst. 2020, $190,105337$. [CrossRef]

58. Bogaard, T.; Hollink, L.; Wielemaker, J.; Hardman, L.; Ossenbruggen, J.V. Searching for old news: User interests and behavior within a national collection. In Proceedings of the 2019 Conference on Human Information Interaction and Retrieval, Scotland, UK, 10-14 March 2019; pp. 113-121.

59. Le T.K.; Ninh, V.T.; Dang-Nguyen, D.T.; Tran, M.T.; Zhou, L.; Redondo, P.; Smyth, S.; Gurrin, C. LifeSeeker: Interactive Lifelog Search Engine at LSC 2019. In Proceedings of the ACM Workshop on Lifelog Search Challenge, Ottawa, ON, Canada, 10-13 June 2019; pp. 37-40.

60. Harris, D.R. Modeling Integration and Reuse of Heterogeneous Terminologies in Faceted Browsing Systems. In Proceedings of the 2016 IEEE 17th International Conference on Information Reuse and Integration (IRI), Pittsburgh, PA, USA, 28-30 July 2016; pp. 58-66.

61. Dou, Z.; Jiang, Z.; Hu, S.; Wen, J.-R.; Song, R. Automatically mining facets for queries from their search results. IEEE Trans. Knowl. Data Eng. 2016, 28, 385-397. [CrossRef]

62. Tzitzikas, Y.; Armenatzoglou, N.; Papadakos, P. FleXplorer: A framework for providing faceted and dynamic taxonomy-based information exploration. In Proceedings of the 2008 19th International Workshop on Database and Expert Systems Applications, Turin, Italy, 1-5 September 2008; pp. 392-396.

63. Harris, D.R. Modeling reusable and interoperable faceted browsing systems with category theory. In Proceedings of the 2015 IEEE International Conference on Information Reuse and Integration (IRI), San Francisco, CA, USA, 13-15 August 2015 ; pp. 388-395.

64. Miotto, R.; Jiang, S.; Weng, C. eTACTS: A method for dynamically filtering clinical trial search results. J. Biomed. Inform. 2013, 46, 1060-1067. [CrossRef]

65. Lee, B.; Smith, G.; Robertson, G.G.; Czerwinski, M.; Tan, D.S. FacetLens: Exposing trends and relationships to support sensemaking within faceted datasets. In Proceedings of the SIGCHI Conference on Human Factors in Computing Systems, Boston, MA, USA, 4-9 April 2009; pp. 1293-1302.

66. Henry, M.J.; Hampton, S.; Endert, A.; Roberts, I.; Payne, D. Multifacet: A faceted interface for browsing large multimedia collections. In Proceedings of the 2013 IEEE International Symposium on Multimedia, Anaheim, CA, USA, 9-11 December 2013; pp. 347-350.

67. Kokolaki, A.; Tzitzikas, Y. Facetize: An Interactive Tool for Cleaning and Transforming Datasets for Facilitating Exploratory Search. arXiv 2018, arXiv:1812.10734.

68. Dachselt, R.; Frisch, M.; Weiland, M. FacetZoom: A continuous multi-scale widget for navigating hierarchical metadata. In Proceedings of the SIGCHI Conference on Human Factors in Computing Systems, Florence, Italy, 5-10 April 2008; pp. 1353-1356.

69. Zong, N.; Kim, H.-G.; Nam, S. Constructing faceted taxonomy for heterogeneous entities based on object properties in linked data. Data Knowl. Eng. 2017, 112, 79-93. [CrossRef]

70. Mauro, N.; Ardissono, L.; Hu, Z.F. Multi-faceted Trust-based Collaborative Filtering. In Proceedings of the 27th ACM Conference on User Modeling, Adaptation and Personalization, Larnaca, Cyprus, 9-12 June 2019; pp. 216-224.

71. Rohatgi, S.; Karishma, Z.; Chhay, J.; Keesara, S.R.R.; Wu, J.; Caragea, C.; Giles, C.L. Covidseer: Extending the CORD-19 dataset. In Proceedings of the ACM Symposium on Document Engineering 2020, Virtual Event, 29 September-1 October 2020; pp. 1-4.

72. Qian, K.; Danilevsky, M.; Katsis, Y.; Kawas, B.; Oduor, E.; Popa, L.; Li, Y. XNLP: A Living Survey for XAI Research in Natural Language Processing. In Proceedings of the 26th International Conference on Intelligent User Interfaces, College Station, TX, USA, 13-17 April 2021; pp. 78-80.

73. Trottnow, J.; Greenly, W.; Shaw, C.; Hudson, S.; Helzle, V.; Vera, H.; Ring, D. Sauce: Asset libraries of the future. In Proceedings of the Digital Production Symposium, Virtual, 11-13 August 2020; pp. 1-5.

74. Cao, R.; Lee, R.K.-W.; Hoang, T.-A. DeepHate: Hate speech detection via multi-faceted text representations. In Proceedings of the 12th ACM Conference on Web Science, Southampton, UK, 6-10 July 2020; pp. 11-20.

75. Lee, B.C.; Weld, D.S. Newspaper navigator: Open faceted search for 1.5 million images. In Proceedings of the Adjunct Publication of the 33rd Annual ACM Symposium on User Interface Software and Technology, Virtual, 20-23 October 2020; pp. 120-122.

76. Manioudakis, K.; Tzitzikas, Y. Faceted Search with Object Ranking and Answer Size Constraints. Acm Trans. Inf. Syst. (TOIS) 2020, 39, 1-33. [CrossRef]

77. Sánchez-Cervantes, J.L.; Colombo-Mendoza, L.O.; Alor-Hernández, G.; García-Alcaráz, J.L.; Álvarez-Rodríguez, J.M.; RodríguezGonzález, A. LINDASearch: A faceted search system for linked open datasets. Wirel. Netw. 2020, 26, 5645-5663. [CrossRef] 
78. Stadler, C.; Bin, S.; Wenige, L.; Bühmann, L.; Lehmann, J. Schema-agnostic SPARQL-driven faceted search benchmark generation. J. Web Semant. 2020, 65, 100614. [CrossRef]

79. Papadakos, P.; Tzitzikas, Y. Hippalus: Preference-enriched Faceted Exploration. In Proceedings of the EDBT/ICDT Workshops, Athens, Greece, 24-28 March 2014.

80. Duan, L.; Li, W.; Tsang, I.W.-H.; Xu, D. Improving web image search by bag-based reranking. IEEE Trans. Image Process. 2011, 20, 3280-3290. [CrossRef]

81. Fergus, R.; Fei-Fei, L.; Perona, P.; Zisserman, A. Learning object categories from Google's image search. In Proceedings of the Tenth IEEE International Conference on Computer Vision (ICCV'05), Beijing, China, 17-21 October 2005.

82. Bredin, H.; Roy, A.; Le, V.-B.; Barras, C. Person instance graphs for mono-, cross-and multi-modal person recognition in multimedia data: Application to speaker identification in TV broadcast. Int. J. Multimed. Inf. Retr. 2014, 3, 161-175. [CrossRef]

83. Dix, A. Introduction to information visualisation. In Promise Winter School; Springer: Berlin/Heidelberg, Germany, $2012 ;$ pp. 1-27.

84. Simonini, G.; Zhu, S. Big data exploration with faceted browsing. In Proceedings of the 2015 International Conference on High Performance Computing \& Simulation (HPCS), Amsterdam, The Netherlands, 20-24 July 2015; pp. 541-544.

85. Seifert, C.; Jurgovsky, J.; Granitzer, M. FacetScape: A visualization for exploring the search space. In Proceedings of the 2014 18th International Conference on Information Visualisation (IV), Paris, France, 16-18 July 2014; pp. 94-101.

86. Kucher, K.; Kerren, A. Text visualization techniques: Taxonomy, visual survey, and community insights. In Proceedings of the 2015 IEEE Pacific Visualization Symposium (PacificVis), Hangzhou, China, 14-17 April 2015; pp. 117-121.

87. Kajiyama, T. Evaluation of Improved Botanical Search Application for Elementary School Students. In Proceedings of the 2020 14th International Conference on Ubiquitous Information Management and Communication (IMCOM), Taichung, Taiwan, 3-5 January 2020; pp. 1-5.

88. Dornauer, V.; Jahn, F.; Hoeffner, K.; Winter, A.; Ammenwerth, E. Use of Natural Language Processing for Precise Retrieval of Key Elements of Health IT Evaluation Studies. In The Importance of Health Informatics in Public Health during a Pandemic; IOS Press: Amsterdam, The Netherlands, 2020; pp. 95-98.

89. Rauch, M.; Klieber, W.; Wozelka, R.; Singh, S.; Sabol, V. Knowminer search-a multi-visualisation collaborative approach to search result analysis. In Proceedings of the 2015 19th International Conference on Information Visualisation, Barcelona, Spain, 22-24 July 2015; pp. 379-385.

90. Dörk, M.; Riche, N.H.; Ramos, G.; Dumais, S. Pivotpaths: Strolling through faceted information spaces. IEEE Trans. Vis. Comput. Graph. 2012, 18, 2709-2718. [CrossRef] [PubMed]

91. Luo, Y.; Qin, X.; Chai, C.; Tang, N.; Li, G.; Li, W. Steerable self-driving data visualization. IEEE Trans. Knowl. Data Eng. 2020. [CrossRef]

92. Sonntag, D.; Profitlich, H.-J. An architecture of open-source tools to combine textual information extraction, faceted search and information visualisation. Artif. Intell. Med. 2019, 93, 13-28. [CrossRef]

93. Mauro, N.; Ardissono, L.; Lucenteforte, M. Faceted search of heterogeneous geographic information for dynamic map projection. Inf. Process. Manag. 2020, 57, 102257. [CrossRef]

94. Tran, L.-D.; Nguyen, M.-D.; Binh, N.T.; Lee, H.; Gurrin, C. Myscéal: An Experimental Interactive Lifelog Retrieval System for LSC'20. In Proceedings of the Third Annual Workshop on Lifelog Search Challenge, Dublin, Ireland, 9 June 2020 ; pp. $23-28$.

95. Chen, C.; Feng, S.; Xing, Z.; Liu, L.; Zhao, S.; Wang, J. Gallery DC: Design Search and Knowledge Discovery through Auto-created GUI Component Gallery. Proc. ACM Hum. Comput. Interact. 2019, 3, 1-22. [CrossRef]

96. Heim, P.; Ziegler, J. Faceted visual exploration of semantic data. In Workshop on Human-Computer Interaction and Visualization; Springer: Berlin/Heidelberg, Germany, 2009; pp. 58-75.

97. Lionakis, P.; Tzitzikas, Y. Pfsgeo: Preference-enriched faceted search for geographical data. In OTM Confederated International Conferences on the Move to Meaningful Internet Systems; Springer: Cham, Switzerland, 2017; pp. 125-143.

98. Huynh, D.F.; Karger, D. Parallax and companion: Set-based browsing for the data web. In Proceedings of the WWW Conference, Madrid, Spain, 8-12 May 2009.

99. Metwally, A.; Pan, J.-Y.; Doan, M.; Faloutsos, C. Scalable community discovery from multi-faceted graphs. In Proceedings of the 2015 IEEE International Conference on Big Data (Big Data), Santa Clara, CA, USA, 29 October-1 November 2015; pp. $1053-1062$.

100. Milne, D.N.; Witten, I.H. A link-based visual search engine for Wikipedia. In Proceedings of the 11th Annual International ACM/IEEE Joint Conference on Digital Libraries, Ottawa, ON, Canada, 13-17 June 2011; pp. 223-226.

101. Dörk, M.; Carpendale, S.; Collins, C.; Williamson, C. VisGets: Coordinated visualizations for web-based information exploration and discovery. IEEE Trans. Vis. Comput. Graph. 2008, 14, 1205-1212. [CrossRef]

102. Keck, M.; Herrmann, M.; Both, A.; Henkens, D.; Groh, R. Exploring Similarity. In Proceedings of the International Conference on Human Interface and the Management of Information, Las Vegas, NV, USA, 15-20 July 2014; pp. 160-171.

103. Heim, P.; Ertl, T.; Ziegler, J. Facet graphs: Complex semantic querying made easy. In The Semantic Web: Research and Applications, Extended Semantic Web Conference; Springer: Berlin/Heidelberg, Germany, 2010; pp. 288-302.

104. Kairam, S.; Riche, N.H.; Drucker, S.; Fernandez, R.; Heer, J. Refinery: Visual exploration of large, heterogeneous networks through associative browsing. Comput. Graph. Forum 2015, 34, 301-310. [CrossRef]

105. Tschinkel, G.; Hafner, R.; Hasitschka, P.; Sabol, V. Using Micro-Visualisations to Support Faceted Filtering of Recommender Results. In Proceedings of the 2016 20th International Conference Information Visualisation (IV), Lisbon, Portugal, 19-22 July 2016; pp. 318-323. 
106. Wongsuphasawat, K.; Moritz, D.; Anand, A.; Mackinlay, J.; Howe, B.; Heer, J. Voyager: Exploratory analysis via faceted browsing of visualization recommendations. IEEE Trans. Vis. Comput. Graph. 2015, 22, 649-658. [CrossRef] [PubMed]

107. Narvala, H.; McDonald, G.; Ounis, I. Receptor: A Platform for Exploring Latent Relations in Sensitive Documents. In Proceedings of the 43rd International ACM SIGIR Conference on Research and Development in Information Retrieval, Xi'an, China, 25-30 July 2020; pp. 2161-2164.

108. Mauro, N.; Izzi, G.; Pellegrino, M.; Ardissono, L.; Gr, C.; Lucenteforte, M.; Segnan, M. Faceted Exploration of Cultural Heritage. In Proceedings of the Adjunct Publication of the 28th ACM Conference on User Modeling, Adaptation and Personalization, Genoa, Italy, 12-18 July 2020; pp. 340-346.

109. Heidari, G.; Ramadan, A.; Stocker, M.; Auer, S. Demonstration of Faceted Search on Scholarly Knowledge Graphs. In Proceedings of the Web Conference 2021, New York, NY, USA, 19-23 April 2021; pp. 685-686.

110. Kelly, D. Methods for evaluating interactive information retrieval systems with users. Found. Trends Inf. Retr. 2009, 3, 1-224. [CrossRef]

111. Xing, D.; Xue, G.-R.; Yang, Q.; Yu, Y. Deep classifier: Automatically categorizing search results into large-scale hierarchies. In Proceedings of the 2008 International Conference on Web Search and Data Mining, Palo Alto, CA, USA, 11-12 February 2008; pp. 139-148.

112. Yogesh, Y.; Bhatia, K.K.; Duhan, N.; Shalu, S. Faceted Search on Amazon Data using Naïve Bayes Approach. In Proceedings of the 2021 International Conference on Computing, Communication, and Intelligent Systems (ICCCIS), Greater Noida, India, 19-20 February 2021; pp. 119-124.

113. Moffat, A.; Zobel, J. Rank-biased precision for measurement of retrieval effectiveness. ACM Trans. Inf. Syst. (TOIS) 2008, 27, 1-27. [CrossRef]

114. Järvelin, K.; Kekäläinen, J. Cumulated gain-based evaluation of IR techniques. ACM Trans. Inf. Syst. (TOIS) 2002, 20, 422-446. [CrossRef]

115. Voorhees, E.M. The TREC-8 question answering track report. In Trec; Citeseer: Princeton, NJ USA, $1999 ;$ pp. 77-82.

116. Buckley, C.; Voorhees, E.M. Retrieval evaluation with incomplete information. In Proceedings of the 27th Annual International ACM SIGIR Conference on Research and Development in Information Retrieval, Sheffield, UK, 25-29 July 2004 ; pp. $25-32$.

117. Buckley, C.; Voorhees, E.M. Evaluating evaluation measure stability. In ACM SIGIR Forum; ACM: New York, NY, USA, 2017; pp. 235-242.

118. Liu, X.; Zhai, C.; Han, W.; Gungor, O. Numerical facet range partition: Evaluation metric and methods. In Proceedings of the 26th International Conference on World Wide Web Companion, Perth, Australia, 3-7 April 2017; pp. 662-671.

119. Schuth, A.; Marx, M. Evaluation methods for rankings of facetvalues for faceted search. In Proceedings of the International Conference of the Cross-Language Evaluation Forum for European Languages, Amsterdam, The Netherlands, 19-22 September 2011; pp. 131-136.

120. Chantamunee, S.; Wong, K.W.; Fung, C.C. An exploration of user-facet interaction in collaborative-based personalized multiple facet selection. Knowl. Based Syst. 2020, 209, 106444. [CrossRef]

121. Pound, J.; Paparizos, S.; Tsaparas, P. Facet discovery for structured web search: A query-log mining approach. In Proceedings of the 2011 ACM SIGMOD International Conference on Management of Data, Athens, Greece, 12-16 June 2011; pp. 169-180.

122. Clarke, C.L.; Craswell, N.; Soboroff, I. Overview of the trec 2009 web track. In Proceedings of the Eighteenth Text REtrieval Conference, TREC 2009, Gaithersburg, MD, USA, 17-20 November 2009.

123. Micinski, K.; Darais, D.; Gilray, T. Abstracting Faceted Execution. In Proceedings of the 2020 IEEE 33rd Computer Security Foundations Symposium (CSF), Boston, MA, USA, 22-26 June 2020; pp. 184-198.

124. Karlson, A.K.; Robertson, G.G.; Robbins, D.C.; Czerwinski, M.P.; Smith, G.R. FaThumb: A facet-based interface for mobile search. In Proceedings of the SIGCHI conference on Human Factors in Computing Systems, Montreal, QC, Canada, 22-27 April 2006; pp. 711-720.

125. Dash, D.; Rao, J.; Megiddo, N.; Ailamaki, A.; Lohman, G. Dynamic faceted search for discovery-driven analysis. In Proceedings of the 17th ACM Conference on Information and Knowledge Management, Napa Valley, CA, USA, 26-30 October 2008; pp. 3-12.

126. O'brien, H.L.; Toms, E.G. Examining the generalizability of the User Engagement Scale (UES) in exploratory search. Inf. Process. Manag. 2013, 49, 1092-1107. [CrossRef]

127. Kong, W.; Allan, J. Extending faceted search to the general web. In Proceedings of the 23rd ACM International Conference on Conference on Information and Knowledge Management, Shanghai, China, 3-7 November 2014; pp. 839-848.

128. Aso, T.; Amagasa, T.; Kitagawa, H. Relation-oriented faceted search method for knowledge bases. In Proceedings of the 22nd International Conference on Information Integration and Web-Based Applications \& Services, Chiang Mai, Thailand, 30 November-2 December 2020; pp. 192-199.

129. Li, C.; Yan, N.; Roy, S.B.; Lisham, L.; Das, G. Facetedpedia: Dynamic generation of query-dependent faceted interfaces for wikipedia. In Proceedings of the 19th International Conference on World Wide Web, Raleigh, NC, USA, 26-30 April 2010; pp. 651-660.

130. Hearst, M.A. Clustering versus faceted categories for information exploration. Commun. ACM 2006, 49, 59-61. [CrossRef]

131. Bartolini, I. A multi-faceted browsing interface for digital photo collections. In Proceedings of the 2009 Seventh International Workshop on Content-Based Multimedia Indexing, Dublin, Ireland, 4-6 September 2009; pp. 237-242. 
132. Smith, G.; Czerwinski, M.; Meyers, B.; Robbins, D.; Robertson, G.; Tan, D.S. FacetMap: A scalable search and browse visualization. IEEE Trans. Vis. Comput. Graph. 2006, 12, 797-804. [CrossRef] [PubMed]

133. Sánchez-Cervantes, J.L.; Alor-Hernández, G.; Paredes-Valverde, M.A.; Rodríguez-Mazahua, L.; Valencia-García, R. NaLa-Search: A multimodal, interaction-based architecture for faceted search on linked open data. J. Inf. Sci. 2020. [CrossRef]

134. Huang, K.; Chen, J.; Liu, C.; Zhang, L. A Comparative Study of the Relationship between the Subjective Difficulty, Objective Difficulty of Search Tasks and Search Behaviors. In Proceedings of the ACM/IEEE Joint Conference on Digital Libraries in 2020, Virtual, 1-5 August 2020; pp. 421-424.

135. Shukla, S.; Hoeber, O. Visually Linked Keywords to Support Exploratory Browsing. In Proceedings of the 2021 Conference on Human Information Interaction and Retrieval, Canberra, ACT, Australia, 14-19 March 2021; pp. 273-277.

136. Niu, X.; Hemminger, B. Analyzing the interaction patterns in a faceted search interface. J. Assoc. Inf. Sci. Technol. 2015, 66, 1030-1047. [CrossRef]

137. Zhang, X.; Liu, J.; Li, Y.; Zhang, Y. How usable are operational digital libraries: A usability evaluation of system interactions. In Proceedings of the 1st ACM SIGCHI Symposium on Engineering Interactive Computing Systems, Pittsburgh, PA, USA, 15-17 July 2009; pp. 177-186.

138. Jansen, B.J.; Spink, A. How are we searching the World Wide web? A comparison of nine search engine transaction logs. Inf. Process. Manag. 2006, 42, 248-263. [CrossRef]

139. Heuwing, B.; Mandl, T.; Womser-Hacker, C. Evaluating a tool for the exploratory analysis of usability information using a cognitive walkthrough method. In Proceedings of the 5th Information Interaction in Context Symposium, Regensburg, Germany, 26-30 August 2014; pp. 243-246.

140. Hughes-Morgan, K.; Wilson, M.L. Information vs. interaction: Examining different interaction models over consistent metadata. In Proceedings of the 4th Information Interaction in Context Symposium, Nijmegen, The Netherlands, 21-24 August 2012; pp. 72-81.

141. Tsakonas, G.; Papatheodorou, C. Exploring usefulness and usability in the evaluation of open access digital libraries. Inf. Process. Manag. 2008, 44, 1234-1250. [CrossRef]

142. Hwang, Y. Measuring information behavior performance inside a company: A case study. Inf. Res. 2011, 16, 12-16.

143. Kong, W.; Allan, J. Extracting query facets from search results. In Proceedings of the 36th International ACM SIGIR Conference on Research and Development in Information Retrieval, Dublin, Ireland, 28 July-1 August 2013; pp. 93-102.

144. Liu, T.-Y. Learning to rank for information retrieval. Found. Trends Inf. Retr. 2009, 3, 225-331. [CrossRef]

145. Grotov, A.; de Rijke, M. Online Learning to Rank for Information Retrieval. In Proceedings of the 39th International ACM SIGIR Conference on Research and Development in Information Retrieval, Pisa, Italy, 17-21 July 2016.

146. Afeefi, A. NavAS: Navigation Approaches for Answer Sets. In Proceedings of the 2019 IEEE Jordan International Joint Conference on Electrical Engineering and Information Technology (JEEIT), Amman, Jordan, 9-11 April 2019; pp. 79-84.

147. Greiner-Petter, A.; Schubotz, M.; Müller, F.; Breitinger, C.; Cohl, H.; Aizawa, A.; Gipp, B. Discovering Mathematical Objects of Interest-A Study of Mathematical Notations. In Proceedings of the Web Conference 2020, Taipei, Taiwan, 20-24 April 2020; pp. 1445-1456.

148. Ben-Yitzhak, O.; Golb, N.; Har'El, N.; Lempel, R.; Neumann, A.; Ofek-Koifman, S.; Sheinwald, D.; Shekita, E.; Sznajder, B.; Yogev, S. Beyond basic faceted search. In Proceedings of the 2008 International Conference on Web Search and Data Mining, Palo Alto, CA, USA, 11-12 February 2008; pp. 33-44.

149. Roy, S.B.; Wang, H.; Nambiar, U.; Das, G.; Mohania, M. Dynacet: Building dynamic faceted search systems over databases. In Proceedings of the 2009 IEEE 25th International Conference on Data Engineering, Shanghai, China, 29 March-2 Apri 2009; pp. 1463-1466.

150. Vandic, D.; Aanen, S.; Frasincar, F.; Kaymak, U. Dynamic Facet Ordering for Faceted Product Search Engines. IEEE Trans. Knowl. Data Eng. 2017, 29, 1004-1016. [CrossRef]

151. Stefaner, M.; Urban, T.; Seefelder, M. Elastic lists for facet browsing and resource analysis in the enterprise. In Proceedings of the 2008 19th International Workshop on Database and Expert Systems Applications, Turin, Italy, 1-5 September 2008; pp. 397-401.

152. Kim, H.-J.; Zhu, Y.; Kim, W.; Sun, T. Dynamic faceted navigation in decision making using Semantic web technology. Decis. Support Syst. 2014, 61, 59-68. [CrossRef]

153. Sacco, G.M. Research results in dynamic taxonomy and faceted search systems. In Proceedings of the 18th International Workshop on Database and Expert Systems Applications (DEXA 2007), Regensburg, Germany, 3-7 September 2007; pp. 201-206.

154. Luca, E.W.D.; Nürnberger, A. Supporting information retrieval on mobile devices. In Proceedings of the 7th International Conference on Human Computer Interaction with Mobile Devices \& Services, Salzburg, Austria, 19-22 September 2005; pp. 347348 .

155. Gollub, T.; Hutans, L.; Jami, T.A.; Stein, B. Exploratory Search Pipes with Scoped Facets. In Proceedings of the 2019 ACM SIGIR International Conference on Theory of Information Retrieval, Santa Clara, CA, USA, 2-5 October 2019; pp. $245-248$.

156. Ramya, R.; Raju, N.; Sejal, N.; Venugopal, K.; Iyengar, S.; Patnaik, L. Automatic Extraction of Facets for User Queries [AEFUQ]. In Proceedings of the 2019 Fifteenth International Conference on Information Processing (ICINPRO), Bengaluru, India, 20-22 December 2019; pp. 1-6.

157. Niu, N.; Mahmoud, A.; Yang, X. Faceted navigation for software exploration. In Proceedings of the 2011 IEEE 19 th International Conference on Program Comprehension, Kingston, ON, Canada, 22-24 June 2011; pp. 193-196. 
158. Xu, B.; Zhuge, H. Automatic faceted navigation. Future Gener. Comput. Syst. 2014, 32, 187-197. [CrossRef]

159. Charleer, S.; Klerkx, J.; Duval, E.; Laet, T.D.; Verbert, K. Faceted search on coordinated tablets and tabletop: A comparison. In Proceedings of the 8th ACM SIGCHI Symposium on Engineering Interactive Computing Systems, Brussels, Belgium, 21-24 June 2016; pp. 165-170.

160. Hearst, M. Design recommendations for hierarchical faceted search interfaces. In ACM SIGIR Workshop on Faceted Search; ACM: New York, NY, USA, 2006; pp. 1-5.

161. Wu, H.; Zubair, M.; Maly, K. Collaborative classification of growing collections with evolving facets. In Proceedings of the Eighteenth Conference on Hypertext and Hypermedia, Manchester, UK, 10-12 September 2007; pp. 167-170.

162. Siddiqui, T.; Ren, X.; Parameswaran, A.; Han, J. FacetGist: Collective Extraction of Document Facets in Large Technical Corpora. In Proceedings of the 25th ACM International on Conference on Information and Knowledge Management, Indianapolis, IN, USA, 24-28 October 2016; pp. 871-880.

163. Chaudhuri, S.; Das, G.; Hristidis, V.; Weikum, G. Probabilistic information retrieval approach for ranking of database query results. ACM Trans. Database Syst. (TODS) 2006, 31, 1134-1168. [CrossRef]

164. Hristidis, V.; Hwang, H.; Papakonstantinou, Y. Authority-based keyword search in databases. ACM Trans. Database Syst. (TODS) 2008, 33, 1-40. [CrossRef]

165. Dakka, W.; Ipeirotis, P.G.; Wood, K.R. Automatic construction of multifaceted browsing interfaces. In Proceedings of the 14th ACM International Conference on Information and Knowledge Management, Las Vegas, CA, USA, 24-27 August 2005; pp. 768-775.

166. Koren, J.; Zhang, Y.; Liu, X. Personalized interactive faceted search. In Proceedings of the 17th International Conference on World Wide Web, Beijing, China, 21-25 April 2008; pp. 477-486.

167. Wagner, A.; Ladwig, G.; Tran, T. Browsing-oriented semantic faceted search. In Proceedings of the Database and Expert Systems Applications, Toulouse, France, 29 August-2 September 2011; pp. 303-319.

168. Gomadam, K.; Ranabahu, A.; Nagarajan, M.; Sheth, A.P.; Verma, K. A faceted classification based approach to search and rank web apis. In Proceedings of the 2008 IEEE International Conference on Web Services, Beijing, China, 23-26 September 2008; pp. 177-184.

169. Grineva, M.; Grinev, M.; Lizorkin, D.; Boldakov, A.; Turdakov, D.; Sysoev, A.; Kiyko, A. Blognoon: Exploring a topic in the blogosphere. In Proceedings of the 20th International Conference Companion on World Wide Web, Hyderabad, India, 28 March-1 April 2011.

170. Gabrilovich, E.; Markovitch, S. Wikipedia-based semantic interpretation for natural language processing. J. Artif. Intell. Res. 2009, 34, 443-498. [CrossRef]

171. Wang, H.; Liu, Q.; Xue, G.-R.; Yu, Y.; Zhang, L.; Pan, Y. Dataplorer: A scalable search engine for the data web. In Proceedings of the 18th International Conference on World Wide Web, Madrid, Spain, 20-24 April 2009; pp. 1079-1080.

172. Glowacka, D.; Ruotsalo, T.; Konuyshkova, K.; Kaski, S.; Jacucci, G. Directing exploratory search: Reinforcement learning from user interactions with keywords. In Proceedings of the 2013 International Conference on Intelligent User Interfaces, Santa Monica, CA, USA, 19-22 March 2013; pp. 117-128.

173. Kern, D.; van Hoek, W.; Hienert, D. Evaluation of a search interface for preference-based ranking: Measuring user satisfaction and system performance. In Proceedings of the 10th Nordic Conference on Human-Computer Interaction, Oslo, Norway, 29 September-3 October 2018; pp. 184-194.

174. Kong, W. Extending Faceted Search to the Open-Domain Web; University of Massachusetts Libraries: Amherst, MA, USA, 2016.

175. Liu, K.; Tan, H.B.K. Faceted bug report search with topic model. In Proceedings of the 2014 IEEE 38th Annual Computer Software and Applications Conference, Vasteras, Sweden, 21-25 July 2014; pp. 123-128.

176. Van Zwol, R.; Sigurbjornsson, B.; Adapala, R.; Garcia Pueyo, L.; Katiyar, A.; Kurapati, K.; Muralidharan, M.; Muthu, S.; Murdock, V.; Ng, P.; et al. Faceted exploration of image search results. In Proceedings of the 19th International Conference on World Wide Web, Raleigh, NC, USA, 26-30 April 2010; pp. 961-970.

177. Bonino, D.; Corno, F.; Farinetti, L. Faset: A set theory model for faceted search. In Proceedings of the 2009 IEEE/WIC/ACM International Joint Conference on web Intelligence and Intelligent Agent Technology, Milan, Italy, 15-18 September 2009; pp. $474-481$.

178. Kohno, I.; Miyazaki, Y.; Hara, M.; Ikegami, T. InfoCruise: Information Navigation Presenting a Focus Facet Based on Context. In Proceedings of the First International Conference on Advances in Computer-Human Interaction, Martinique, France, 10-15 February 2008; pp. 45-52.

179. Tzitzikas, Y.; Dimitrakis, E. Preference-enriched Faceted Search for Voting Aid Applications. IEEE Trans. Emerg. Top. Comput. 2016, 7, 218-229. [CrossRef]

180. Zwol, R.V.; Pueyo, L.G.; Muralidharan, M.; Sigurbjornsson, B. Ranking entity facets based on user click feedback. In Proceedings of the 2010 IEEE Fourth International Conference on Semantic Computing, Pittsburgh, PA, USA, 22-24 September 2010; pp. 192-199.

181. Kitsos, I.; Magoutis, K.; Tzitzikas, Y. Scalable entity-based summarization of web search results using MapReduce. Distrib. Parallel Databases 2014, 32, 405-446. [CrossRef]

182. Friedrich, J.; Lindemann, C.; Petrifke, M. Utilizing query facets for search result navigation. In Proceedings of the 201526 th International Workshop on Database and Expert Systems Applications (DEXA), Valencia, Spain, 1-4 September 2015; pp. 271-275. 
183. Ravana, S.D.; Samimi, P.; Ashtyani, P.D. Exploring relevance assessment using crowdsourcing for faceted and ambiguous queries. In Proceedings of the 2014 Science and Information Conference, London, UK, 27-29 August 2014; pp. 771-776.

184. Wu, S.; Huang, C.; Li, L.; Crestani, F. Fusion-based methods for result diversification in web search. Inf. Fusion 2019, 45, 16-26. [CrossRef]

185. Komamizu, T.; Amagasa, T.; Kitagawa, H. Faceted navigation framework for XML data. Int. J. Web Inf. Syst. 2012, 8, 348-370. [CrossRef]

186. Amagasa, T.; Ishii, N.; Yoshie, T.; Tatebe, O.; Sato, M.; Kitagawa, H. A faceted-navigation system for QCDml ensemble XML data. In Proceedings of the 2010 International Conference on P2P, Parallel, Grid, Cloud and Internet Computing, Fukuoka, Japan, 4-6 November 2010; pp. 132-139.

187. Komamizu, T.; Amagasa, T.; Kitagawa, H. Facet-value extraction scheme from textual contents in XML data. Int. J. Web Inf. Syst. 2015, 11, 270-290. [CrossRef]

188. Matthes, F.; Neubert, C.; Steinhoff, A. Multi-faceted context-dependent knowledge organisation with TACKO. In Proceedings of the 12th International Conference on Knowledge Management and Knowledge Technologies, Graz, Austria, 5-7 September 2012; p. 9.

189. Tzitzikas, Y. Evolution of faceted taxonomies and CTCA expressions. Knowl. Inf. Syst. 2007, 13, 337-365. [CrossRef]

190. Al-Aqrabi, H.; Liu, L.; Hill, R.; Cui, L.; Li, J. Faceted Search in Business Intelligence on the Cloud. In Proceedings of the 2013 IEEE International Conference on Green Computing and Communications and IEEE Internet of Things and IEEE Cyber, Physical and Social Computing, Beijing, China, 20-23 August 2013; pp. 842-849.

191. Bergamaschi, S.; Simonini, G.; Zhu, S. Enhancing big data exploration with faceted browsing. In Classification, (Big) Data Analysis and Statistical Learning; Springer: Berlin/Heidelberg, Germany, 2018; pp. 13-21.

192. Harris, D.R.; Kavuluru, R.; Jaromczyk, J.W.; Johnson, T.R. Rapid and reusable text visualization and exploration development with delve. AMIA Summits Transl. Sci. Proc. 2017, 2017, 139. [PubMed]

193. Viegas, F.B.; Wattenberg, M.; Feinberg, J. Participatory visualization with wordle. IEEE Trans. Vis. Comput. Graph. 2009, 15, 1137-1144. [CrossRef]

194. Ham, F.V.; Wattenberg, M.; Viégas, F.B. Mapping text with phrase nets. IEEE Trans. Vis. Comput. Graph. 2009, 15, $1169-1176$.

195. Wattenberg, M.; Viégas, F.B. The word tree, an interactive visual concordance. IEEE Trans. Vis. Comput. Graph. 2008, 14, 1221-1228. [CrossRef]

196. Catarci, T.; Kimani, S. Human-computer interaction view on information retrieval evaluation. In Promise Winter School; Springer: Berlin/Heidelberg, Germany, 2012; pp. 48-75. 